\title{
An Experimental Study of Momentum and Heavy Particle Transport in a Trellised Agricultural Canopy
}

3

\author{
Nathan E. Miller ${ }^{\mathrm{a}}$, Rob Stoll ${ }^{\mathrm{a}, *}$, Walter Mahafee ${ }^{\mathrm{b}}$, Tara M. Neill ${ }^{\mathrm{b}}$, Eric R. Pardyjak ${ }^{\mathrm{a}}$ \\ ${ }^{a}$ Department of Mechanical Engineering, University of Utah, Salt Lake City, Utah \\ ${ }^{b}$ USDA Agricultural Research Service, Horticulture Crops Research Unit, Corvallis, Oregon
}

\begin{abstract}
Turbulent particle dispersion in plant canopies plays an important role in many agricultural and forestry ecosystems. Most research on dispersion in plant canopies has focused on dispersal patterns in homogeneous dense canopies and/or on patterns far from the source. To study near-source particle dispersion in a sparse agricultural canopy, a series of point-source particle release events was conducted in a commercial vineyard. Analysis of the wind velocity data indicated that the majority of the flow in the open spaces between the vine rows was channeled parallel to the vine rows regardless of the direction of the mean wind above the canopy. Although this channeling led to significant turning of the mean velocity, profiles of turbulent statistics taken at times when the above-canopy winds were nearly parallel to the vine rows showed similar behavior to canopy flow profiles in previous studies. The particle release events were conducted using fluorescent microspheres with similar physical characteristics to the spores of multiple airborne fungal pathogens of grapes (diameter $=10-45 \mu \mathrm{m}$, density $\left.=1.0 \mathrm{~g} / \mathrm{cm}^{3}\right)$. Microspheres were released from two vertical positions within the canopy and monitored using a dense three dimensional impaction trap array in the nearsource region (1-5 canopy heights downwind). The shape of the microsphere plumes was strongly impacted by the flow channeling within the canopy. Specifically, the plumes' maximum concentrations were typically channelled down the aisle in which they originated. The spanwise concentration profile also tended to be skewed from the release aisle toward the mean wind direction above the canopy. This was believed to be caused by the wind directional shear created by the difference between the mean wind direction above the canopy and the vine row direction as well as the filtering effects of the plants themselves.
\end{abstract}

Keywords: canopy flow, dispersion, particle transport, vineyard experiments

\section{Introduction}

Turbulent dispersion in a plant canopy differs from dispersion in the free atmospheric boundary layer (ABL) because of the interplay between the canopy architecture and the local meteorological conditions. Within plant canopies, enhanced turbulent intermittency (Finnigan, 2000) can drastically alter dispersion gradients (Ferrandino, 1993). In addition, the canopy's plant density has a direct impact on the canopyatmosphere interaction and the characteristics of dispersion (Bailey et al., 2014).

Most previous studies of momentum transport and particle dispersion in plant canopies have focused on dense canopies (e.g., Aylor and Ferrandino, 1989; Dwyer et al., 1997; Finnigan, 2000; Thomas and Foken, 2007; Yue et al., 2007; Su et al., 1998) or on forest

Preprint submitted to Ag and Forest Meteorol

May 15, 2015

* Corresponding author

Email addresses: nmiller@eng.utah.edu (Nathan E. Miller), rstoll@eng.utah.edu (Rob Stoll ), walt.mahaffee@ars.usda.gov (Walter Mahafee), tara.neill@ars.usda.gov (Tara M. Neill), pardyjak@eng.utah.edu (Eric R. Pardyjak) 
clearings and edge flows (e.g., Yang et al., 2006; Dupont and Brunet, 2008; Detto et al., 2008; Cassiani et al., 2008). Significantly fewer experimental (e.g., Weiss and Allen, 1976; Verhoef et al., 1997; Novak et al., 2000; Böhm et al., 2013) and numerical (e.g., Su et al., 2008; Huang et al., 2009; Bailey and Stoll, 2013; Bailey et al., 2014) studies have focused on sparse canopies where the canopy had discontinuities at length scales on the order of the canopy height. These few primarily focused on momentum transport with the experimental studies often using wind tunnel or water channel canopy models with a single type of canopy architecture (e.g., arrays of cylinders, see: Raupach et al., 1980; Judd et al., 1996; Novak et al., 2000; Poggi et al., 2004; Böhm et al., 2013). One exception to this is the experiment of Patton et al. (2011) which reported measurements of momentum transport in a sparse walnut orchard. In the numerical studies, the analysis typically treated the canopy as horizontally homogenous (e.g., Dupont and Brunet, 2008; Huang et al., 2009).

The majority of the experimental field studies that have examined particle transport in plant canopies have been performed in dense canopies (e.g., Raynor et al., 1974; Aylor and Ferrandino, 1989; Gleicher et al., 2014). In addition to a focus on dense canopies, the information about particle plume spread dynamics has often been limited by low particle sampling densities that are often only along a single arc or plane. The studies have used their data for applications including the validation of Lagrangian particle models (Aylor et al., 2001), average canopy vertical particle flux modeling (Chamecki et al., 2012), and maximum concentration tracking (Hanna and Baja, 2009). A few studies have used three-dimensional sampling arrays but have focused on more qualitative spread evaluation (Raynor et al., 1974) or on model validation and not specifically on the three-dimensional plume shape (Gleicher et al., 2014). These studies were also performed in dense canopies and did not use dense enough arrays to characterize the plume shape in the near-source region. None of these studies examined both momentum and particle transport in a sparse plant canopy.

Exceptions to the focus on dense canopies include Novak et al. (2000) and Poggi et al. (2004) which investigated the effect of canopy density on momentum transport. These studies did not investigate the density effects on particle transport and were still performed on relatively homogenous canopies. Considerably fewer studies have focused on sparse non-homogenous canopies (e.g., Weiss and Allen, 1976; Bailey and Stoll, 2013; Bailey et al., 2014). Bailey and Stoll (2013) and Bailey et al. (2014) used numerical simulations to study transport within two-dimensional row oriented canopies when the wind was blowing orthogonally to the row direction. They found that momentum and particle transport in these canopies are functions of canopy architecture. In particular for momentum transport, the horizontal heterogeneity created by the row structure had an impact on second- and third-order momentum statistics, resulted in significant dispersive fluxes in the lower part of the canopy, and preferentially located coherent structure events. When examining massless non-depositing particles, they found that canopy heterogeneity increased vertical particle fluxes, decreased residence time of particles in the canopy, and decreased the persistence of particle motions.

The focus of this study was on sparse perennial agricultural canopies organized into rows. These types of canopies are typified by trellised canopies of Vitis vinifera (grape vineyards). Grape vineyard canopies are approximately two-dimensional with large open spaces creating discontinuities at length scales on the order of the canopy height. This geometry directly impacts the mean velocity field resulting in a rotation of the mean wind towards the row direction (Weiss and Allen, 1976) with direct consequences for vine biophysiology (Tarara et al., 2005). Grape vineyard canopies were of interest due to their direct economic impact (USDA NASS, 2013), the increased use 
of trellised canopies in a variety of crops (Talaie et al., 2011), and because they share many characteristics with other canopies of importance in agricultural and urban applications including wind breaks (Patton et al., 1998; Raupach et al., 2001; Bouvet et al., 2006; Speckart and Pardyjak, 2014) and urban street canyons (Belcher, 2005; Klein et al., 2007; Addepalli and Pardyjak, 2013).

We hypothesized that the sparse geometry of grape vineyard canopies and other canopies with similar characteristics, through its influence on the mean wind and local fluxes, would play a central role in determining particle dispersion dynamics within and above the canopy. Specifically, we expected that the canopy would affect the mean advection direction, the rate of plume spread, and the shape of the spanwise profile of the plume. To test this hypothesis, a field campaign (Sect. 2) was conducted in a vineyard in Western Oregon. Particle transport was studied through a series of controlled particle release experiments using polyethylene microspheres with a size range similar to spores of multiple fungal grape pathogens. A high density, three-dimensional array of samplers was used to collect the microspheres allowing for the plume shape to be investigated in detail. The momentum transport statistics within the vineyard (Sect. 3) and the results of the release events were used to elucidate the canopy's influence on particle dispersion (Sect. 4).

\section{Field Campaign}

The field study was performed in September and October, 2011 in a commercial vineyard in the Willamette valley near Monmouth, Oregon at $\approx 44^{\circ} 49^{\prime} 28.0^{\prime \prime} \mathrm{N}, 123^{\circ}$ $14^{\prime} 17.0^{\prime \prime} \mathrm{W}$. The vineyard is a relatively flat site of $\approx 43$ hectares with vine rows oriented to within $\pm 2^{\circ}$ of true north-to-south. The experiments were conducted in the southeast portion of the field where the plant growth was the most homogeneous. The wind at this location came primarily from the north and southwesterly directions providing a maximum upstream fetch $(>350 \mathrm{~m})$ composed of nearly continuous trellised vines. The terrain had a west-to-east downslope of $\approx 2.4 \%$ and a south to north down slope of $\approx 0.8 \%$.

Throughout the experiment, a meteorological tower (Fig. 1) with four Campbell Scientific CSAT3 sonic anemometers was placed in the aisle between two rows of vines with the anemometers pointing to true north. The anemometers were placed at heights of $5,2.9,1.8$, and $0.8 \mathrm{~m}$. The lowest two anemometers were placed such that the bottom and top of the canopy immediately around the tower were within their sampling volumes. Additionally, the sampling volume of the $1.8 \mathrm{~m}$ anemometer was aligned with the canopy's top-most trellis wire. The anemometers collected tri-directional wind data [streamwise $(u)$, spanwise $(v)$, and vertical $(w)$ ] and the sonic temperature $(T)$ at each height. The meteorological data were recorded $24 \mathrm{hrs} /$ day at $20 \mathrm{~Hz}$ using a Campbell Scientific CR5000 Datalogger.

The surrounding canopy had an average height $(h)$ of $1.90 \mathrm{~m}$ with local variation from one plant to the next (Fig. 1). The vine rows were spaced $\left(r_{s}\right)$ at $2.49 \mathrm{~m}$ on center and were $\approx 0.46 \mathrm{~m}$ wide leaving aisles of $\approx 2 \mathrm{~m}$ wide. The leaf area density ( $L A D$, one-sided area of leaves per canopy volume) profile (Fig. 2) was determined by randomly selecting ten vines within the sample area, counting the number of shoots per vine, and randomly removing a shoot from the left and right of the trunk. Leaves from each shoot were removed and digitally assessed for leaf area using Assess Image Analysis Software (The American Phytopathological Society, St. Paul, MN). The leaf area index ( $L A I$, area of leaves per area of ground) was determined based on the same data and was found to be 1.4 for the whole vineyard block. When an individual row of 

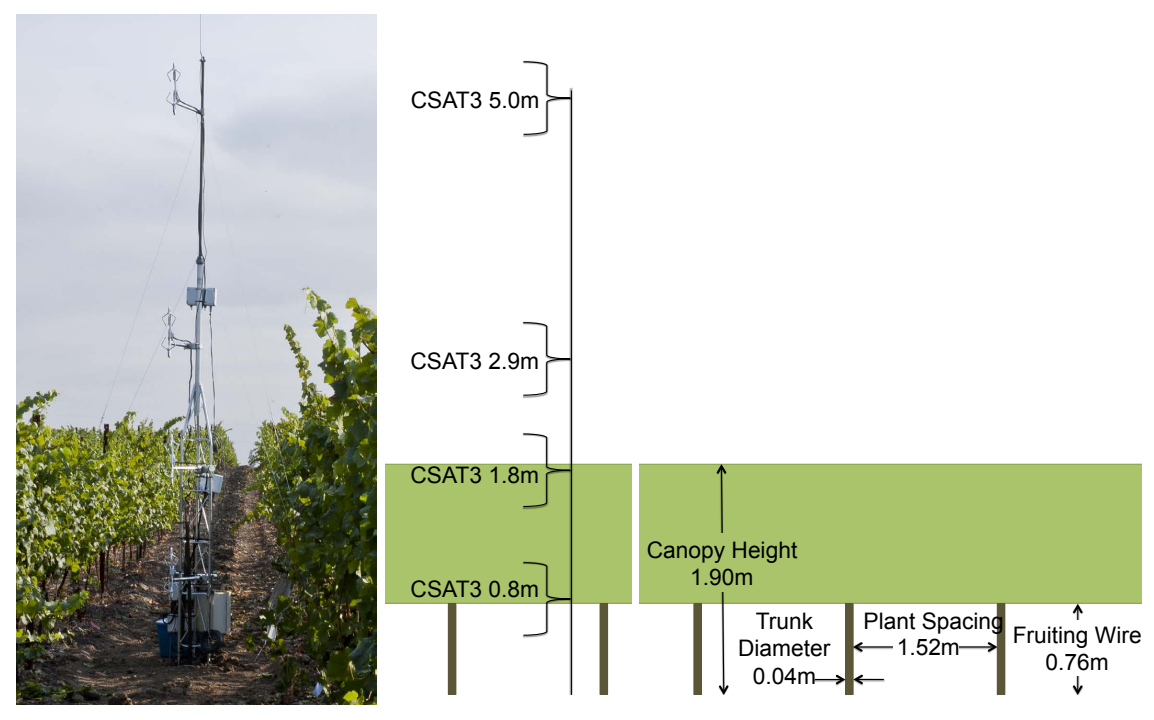

Figure 1: A picture and schematic of the meteorological tower in the vineyard as well as other relevant canopy dimensions. Photographer was facing due South. The top anemometer was at $5.0 \mathrm{~m}$ above the ground and thus $\approx 3.1$ meters above the average canopy top.

vines was considered with the ground directly beneath it the $L A I$ was 7.5. Similar $L A I$ values were reported in Johnson et al. (2003) for vineyards of comparable architecture.

\subsection{Meteorological Data Processing}

The data from the meteorological tower was partitioned into independent continuous 30-minute periods. This period length was sufficient to ensure convergence of flux statistics while maintaining flow steadiness. The mean wind direction for each period at each anemometer height was determined and periods with southerly winds between $165^{\circ}$ and $195^{\circ}$ (coming from behind the tower) at any height were excluded from further analysis. A three-dimensional coordinate rotation was then applied to the wind velocity data of the $z=5 \mathrm{~m}$ anemometer for each period so that only $u$ had an average $>0$ (see Pardyjak and Cuerva, 2007). The wind velocity data for the lower three anemometers were rotated following the rotation determined at the $5 \mathrm{~m}$ anemometer.

Standard relevant statistics including the average streamwise velocity at $z=5 \mathrm{~m}$ $(\bar{u})$ and the mean wind direction at that height $(\overline{w d})$ were determined for each of the 30-minute periods. The friction velocity $\left(u_{*}\right)$ was also determined at the canopy top as,

$$
u_{\star, h}=\left[{\overline{u^{\prime} w^{\prime}}}^{2}+{\overline{v^{\prime} w^{\prime}}}^{2}\right]_{h}^{1 / 4}
$$

where the overlines represent time-averaged mean values taken over the 30-minute period and the primes represent deviations from those means. The subscript $h$ is used to indicate values determined at the canopy height, as is a standard practice for vegetative canopy flows (e.g., Dupont and Patton, 2012; Bailey and Stoll, 2013).

The local atmospheric stability was assessed at the canopy top for each period and was defined as the ratio of $h$ to the Obukhov length $(L)$ determined at that height. The 


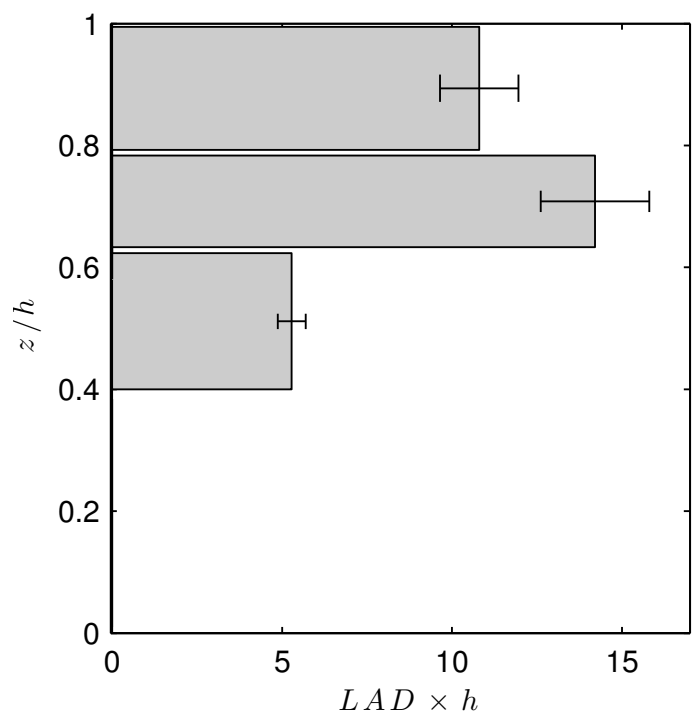

Figure 2: The profile of the leaf area density for the vineyard canopy. The errorbars represent one standard deviation in the LAD among the vines that were tested.

Obukhov length was defined by,

$$
L=\frac{-T_{o} u_{\star, h}^{3}}{\kappa g\left(\overline{w^{\prime} T^{\prime}}\right)_{h}},
$$

where $\kappa$ was the von Kármán constant $(=0.4), T_{o}$ was the mean absolute temperature at $h, g$ was the acceleration due to gravity, and $T$ was linearly detrended to eliminate large diurnal variations. The periods were then grouped into five categories identified as convective (C, $h / L<-0.31)$, moderately convective (MC, $-0.31<h / L \leqslant-0.01$ ), neutral $(\mathrm{N},-0.01<h / L \leqslant 0.03$ ), moderately stable (MS, $0.03<h / L \leqslant 0.6$ ), and stable (S, $h / L>0.6)$ following Mahrt (1998), Launiainen et al. (2007), and Dupont and Patton (2012).

\subsection{Point Release Dispersion Experiments}

Several research studies have used biological particles (e.g., Aylor and Ferrandino, 1989; Klein et al., 2003) or inert particles as biological surrogates (e.g., Hage, 1961; Bouvet et al., 2006) to characterize particle transport in plant canopies. We used fluorescent polyethylene microspheres. Six microsphere release events were conducted at times when $\overline{w d}$ was approximately parallel to the row direction (from the North). Both yellow (UVPMS-BY2-1.00, Cospheric LLC) and orange (UVPMS-BO-1.00, Cospheric LLC) microspheres with $>90 \%$ within the diameter range of 10 to $45 \mu \mathrm{m}$ were released in the canopy during each event. To determine the diameter distributions, microspheres were suspended in $0.05 \% \mathrm{v} / \mathrm{v}$ Tween 20 solution, pipetted onto a hemocytometer plate, and a custom glass cover slip was used to orient the microspheres into one focal plane. Images were then taken using a Leica MZFLIII fluorescence stereo microscope with a 360/40 nm excitation filter, Leica DFC 310FX camera, and 
Table 1: Microsphere release event information for each of the six release events. The duration of each event is listed as well as the mass of each color of microspheres released in that time, and the height from which the different colored microspheres were released.

\begin{tabular}{|c|c|c|c|c|}
\hline Event & Duration (min) & Color & Mass (g) & $H_{r}(\mathrm{~m})$ \\
\hline \multirow{2}{*}{1} & \multirow{2}{*}{5} & $\overline{\mathrm{Y}}$ & 0.20 & 1.7 \\
\hline & & $\mathrm{O}$ & $0.16^{a}$ & 0.7 \\
\hline \multirow{2}{*}{2} & \multirow{2}{*}{5} & $\mathrm{Y}$ & 0.24 & 1.7 \\
\hline & & $\mathrm{O}$ & 0.37 & 0.7 \\
\hline \multirow{2}{*}{3} & \multirow{2}{*}{7} & $\mathrm{Y}$ & 0.16 & 1.2 \\
\hline & & $\mathrm{O}$ & 0.83 & 0.7 \\
\hline \multirow{2}{*}{4} & \multirow{2}{*}{7} & $\mathrm{Y}$ & 0.23 & 1.2 \\
\hline & & $\mathrm{O}$ & 0.59 & 0.7 \\
\hline \multirow{2}{*}{5} & \multirow{2}{*}{7} & $\mathrm{Y}$ & 0.50 & 1.7 \\
\hline & & $\mathrm{O}$ & 0.34 & 0.7 \\
\hline \multirow{2}{*}{6} & \multirow{2}{*}{7} & $\mathrm{Y}$ & 0.73 & 1.7 \\
\hline & & $\mathrm{O}$ & 0.88 & 0.7 \\
\hline
\end{tabular}

Leica Application Suite image capture software (Leica Microsystems, Wetzlar, Germany). The images were analyzed using Assess Image Analysis Software (The American Phytopathological Society, St. Paul, MN). Three microsphere suspensions with two sub-samples per suspension were analyzed and the size distributions determined.

The average diameters for the microspheres were 30.2 and $34.1 \mu \mathrm{m}$ for the yellow and orange spheres, respectively. The diameters corresponding to the microspheres of average mass were 32.8 and $35.5 \mu \mathrm{m}$, respectively. The microspheres' size range included the average hydraulic diameter of Erysiphe necator (grape powdery mildew) spores, $\approx 27 \mu \mathrm{m}$ with a range of $20-36 \mu \mathrm{m}$ (Braun, 1995). Other pathogens of grapes, including Botrytis cinerea (diameters of 8-12 $\mu \mathrm{m}$ Jarvis, 1977) and Plasmopara viticola (diameters of 30-50 $\mu \mathrm{m}$ Waterhouse, 1973), also have sporular hydraulic diameters within the microsphere diameter range. The microspheres had a density $\left(1.005 \mathrm{~g} / \mathrm{cm}^{3}\right)$ similar to many fungal spores (Gregory, 1973). Past studies have found that the terminal settling velocity for unit density, sub-100 $\mu \mathrm{m}$ spheres (Chamberlain, 1975) and for fungal spores (Gregory, 1973) can be accurately predicted using Stokes law. Based on Stokes law the settling velocities for microspheres with diameters of 30 to $35 \mu \mathrm{m}$ vary from $2.8 \mathrm{~cm} / \mathrm{s}$ to $3.9 \mathrm{~cm} / \mathrm{s}$, respectively.

During each release event, the two colors of microspheres were released simultaneously from separate release devices at different heights, $H_{r}$ (Tab. 1). The devices were positioned one above the other within an aisle of the canopy and $\approx 0.25 \mathrm{~m}$ west of the nearest row of vines. The release devices were made of $10.5 \mathrm{~cm}$ polypropylene funnels with press-fit precision machined aluminum tips. An orifice of $210 \mu \mathrm{m}$ in each tip provided a steady flow of microspheres from the funnels when they were vibrated using micro-vibration motors similarly to Bouvet et al. (2006).

The concentration of the released microspheres was sampled at 100 separate locations downwind of the source during each release event. The collection was done using custom rotating arm impaction traps based on Thiessen et al. (2015) and similar to Davis et al. (1997), Aylor and Flesch (2001), and Chamecki et al. (2012). The traps consisted of Mabuchi RF-520C-17410 DC motors supplied with 6 volts $(\sim 2550$ 


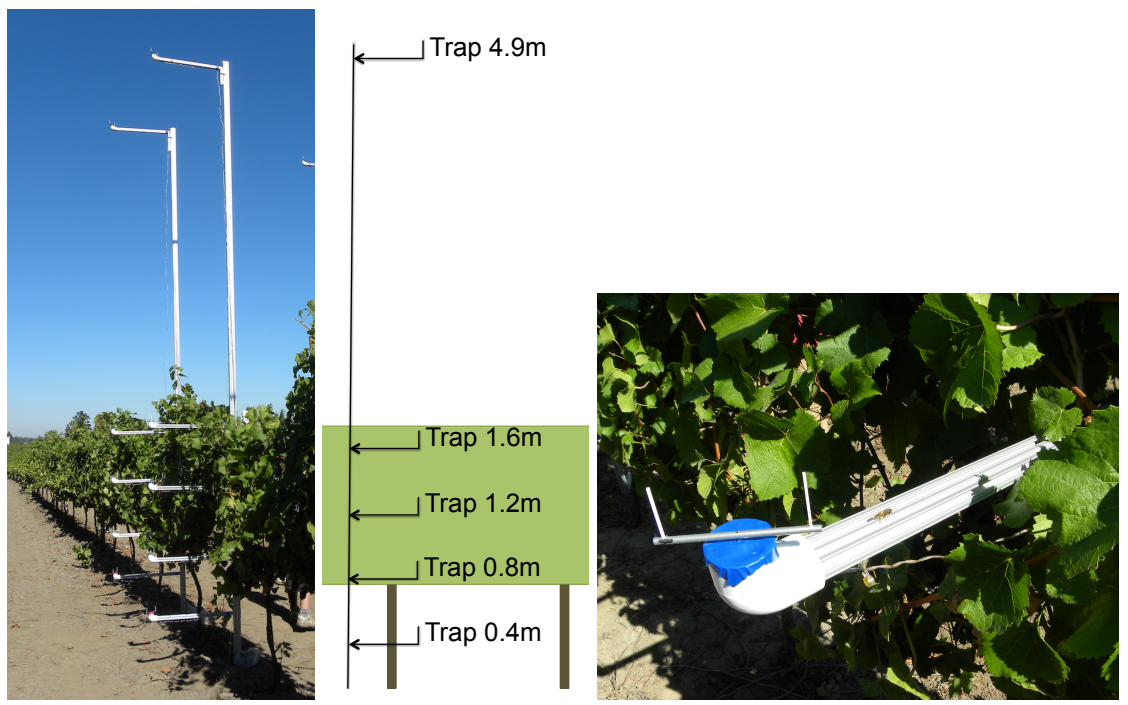

Figure 3: A picture of an impaction trap tower in the vineyard with a schematic showing the impaction trap heights, as well as a picture of an individual rotating arm impaction trap.

RPMs) and a sampling arm with a $38 \mathrm{~mm}$ radius. The two sample rods were $1.5 \times 1.5$ $\times 40 \mathrm{~mm}$ polystyrene coated with a thin film of high vacuum grease (Dow Corning, Midland, MI). Traps were mounted at five different heights on 20 towers. The towers were custom made using 80/20 aluminum T-channel (Fig. 3) and were arranged in an array downwind of the source (Fig. 4). The array consisted of four lines of towers, each oriented orthogonally to the vine row direction at different downwind distances. The impaction traps and release devices were simultaneously turned on and off remotely using controllers on an Xbee wireless mesh network (Digi International Inc.).

The sample rods from each impaction trap were collected then imaged with the fluorescence stereo microscope. To avoid sampling error created by flow alteration at either end of the sampling rods, only $14.2 \mathrm{~mm}$ near the center of the length of the sample rods was used. The collection efficiency of this area of the rods was $>99.98 \%$ according to the modified Stokes theory of Moran et al. (2013).

The number of microspheres, of each color, collected by each impaction trap, for each event, was counted and converted into a scaled concentration, $\Pi$, with units of $\mathrm{m}^{-2}$. It was defined as,

$$
\Pi=\frac{\mathcal{M} \overline{u_{h}}}{\nvdash q}
$$

where $\mathcal{M}$ was the total mass of microspheres collected, $\forall$ was the total volume swept by the trap during the release event, $\overline{u_{h}}$ was a streamwise velocity scale taken as the wind speed at the canopy top, and $q$ was the plume source strength in $\mathrm{g} / \mathrm{s}$ determined from the total mass released and the release event duration. The swept volume was calculated using the speed of each individual impaction trap motor determined in the field with an optical tachometer, the duration of the release event, and the area of the photographed portion of the sample rods. The mass was calculated using the number of microspheres on the sample rods and the average mass of the microspheres. The use of the average mass may have introduced some error into the values for $\Pi$, particularly at locations where few microspheres were collected. The standard deviations of the 


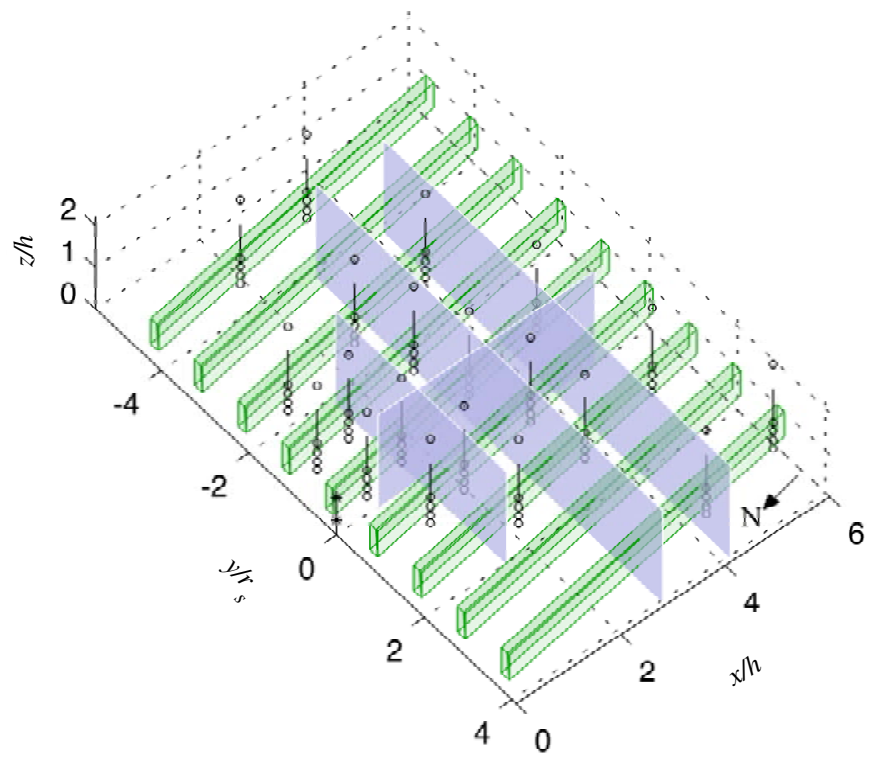

Figure 4: An example schematic of the vineyard (green boxes) showing the three $y-z$ planes and the $x-z$ plane that $\Pi$ was interpolated onto using a tri-linear approach (gray surfaces) for release event number 5. The locations of the individual impaction traps (black circles), and the release mechanisms (black stars) are also shown. The left-hand-rule coordinate system is set such that $x$ follows $\overline{w d}$ and $y$ is perpendicular to it.

microsphere masses were $69 \%$ and $47 \%$ of the means for the yellow and orange microspheres, respectively. Values for $\Pi$ for each impaction trap for each plume are included in the Supplementary Material as Appendix B.

Tri-linear interpolation was used to transfer the $\Pi$ data at each of the trap locations onto five planes of interest within the tower array. Plume shape characteristics like the plume width are typically defined on planes that run orthogonally to the mean plume advection direction which is usually defined by the mean wind direction. The ordinal directions in the canopy were assigned a coordinate system of $+x^{\prime}$ to the south and $+y^{\prime}$ to the west with the origin at the release location. A rotated coordinate system based on $\overline{w d}$ was also defined for each event with the streamwise direction denoted as $x$ and the spanwise axis denoted as $y$ with positive values to the right when viewed from the release location. The first three interpolation planes that $\Pi$ was transferred to were defined orthogonally to the $x$ axis at distances of $x=3.0,5.5$, and $8.0 \mathrm{~m}(1.57 \mathrm{~h}$, $2.89 h$, and $4.21 h)$ and stretching from the lowest impaction trap height $(0.4 \mathrm{~m})$ to the top impaction trap height $(4.9 \mathrm{~m})$ and from the extreme west to extreme east edges of the tower array (Fig. 4). Plume shape parameters are evaluated in Sect. 4 using these $y-z$ planes. The fourth plane was along $x$ and spanned from approximately $x / h=0.8$ to the downwind edge of the tower array, and again from the lowest to the highest impaction trap height. The final interpolation plane was the $x-y$ plane at the height of the impaction traps that were closest to but lower than $H_{r}$.

\section{Momentum Transport Results}

Wind direction and magnitude were examined using wind roses composed of data from all of the 30-minute periods with winds from acceptable directions (Fig. 5). Pe- 

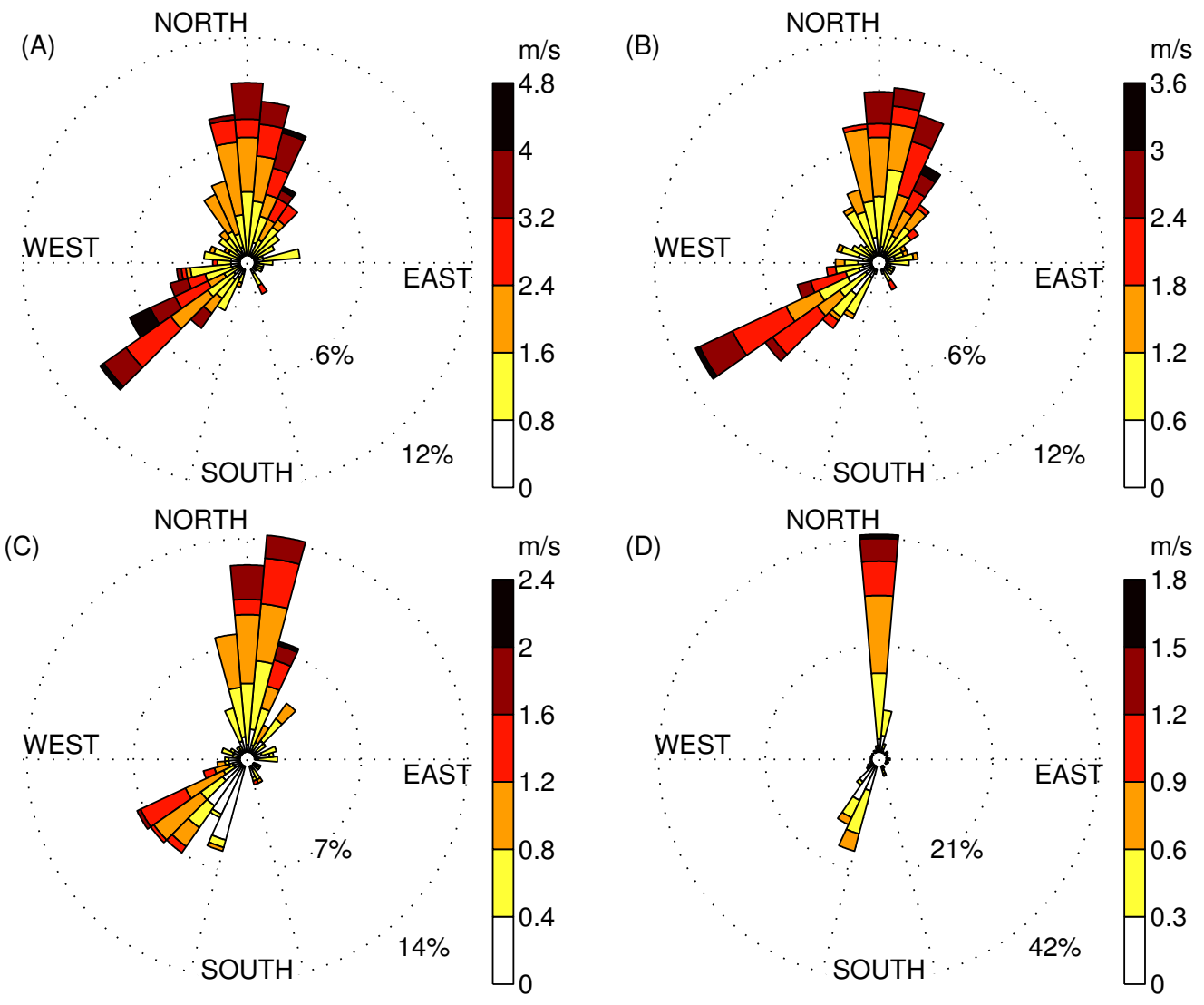

Figure 5: Wind roses of the 399 half-hour periods showing the percentage of periods per directional sector and the percentage of periods in different windspeed categories. (A), (B), (C), and (D) are for the $5 \mathrm{~m}, 2.9$ $\mathrm{m}, 1.8 \mathrm{~m}$, and $0.8 \mathrm{~m}$ anemometers, respectively. Each directional segment is $10^{\circ}$ wide and is centered at multiples of $10^{\circ}$. The segments between $165^{\circ}$ and $195^{\circ}$ were removed due to tower wake interference.

riods with southerly winds between $165^{\circ}$ and $195^{\circ}$ (coming from behind the tower) at any height were excluded from further analysis. The wind velocity generally decreased at lower heights in the canopy and the flow within the canopy was channeled parallel to the vine rows regardless of $\overline{w d}$. While $\overline{w d}$ was primarily from the north and southwesterly directions, the flow in the canopy came primarily from one small sector at due north with a few periods from the south-southwesterly direction. The flow channeling was consistent with previous vineyard observations where the amount of turning was related to the incident wind direction with respect to the canopy elements (Weiss and Allen, 1976; Tarara et al., 2005).

The more convective periods had increased likelihood of northerly winds, while more stable periods were likely to occur with winds out of the west and south. This behavior is attributed to the topography of the region. During convective times (typically during the midday and afternoon hours), the winds exhibited upvalley flow (Whiteman, 2000), blowing up the Willamette Valley from north to south. During stable times (typically at night) the winds had lower speed and blew downslope from the hills to the 
Table 2: The number of 30-minute periods in each of the 10 direction-stability classifications as well as the average streamwise velocity determined at $z=5 \mathrm{~m}$ and at the canopy top, the friction velocity, and the turbulent temperature scale $\left(\theta_{*, h}=-\overline{w^{\prime} T_{h}^{\prime}} u_{*, h}^{-1}\right)$ both determined at the canopy top for the periods in each category. Standard deviations calculated across the periods in each category are included after the \pm symbols. The stability class thresholds were defined in Sect. 2.1.

\begin{tabular}{ccccccc} 
Direction & Stability & Period Count & $\bar{u}(\mathrm{~m} / \mathrm{s})$ & $\overline{u_{h}}(\mathrm{~m} / \mathrm{s})$ & $u_{*, h}(\mathrm{~m} / \mathrm{s})$ & $\theta_{*, h}\left({ }^{\circ}\right)$ \\
\hline \hline \multirow{6}{*}{ Parallel } & C & 3 & $1.48 \pm 0.23$ & $0.75 \pm 0.12$ & $0.19 \pm 0.02$ & $-0.58 \pm 0.21$ \\
& MC & 44 & $2.29 \pm 0.90$ & $1.14 \pm 0.46$ & $0.27 \pm 0.10$ & $-0.19 \pm 0.13$ \\
& N & 10 & $2.51 \pm 0.70$ & $1.25 \pm 0.39$ & $0.28 \pm 0.08$ & $0.003 \pm 0.04$ \\
& S & 24 & $1.45 \pm 0.51$ & $0.63 \pm 0.30$ & $0.14 \pm 0.05$ & $0.08 \pm 0.05$ \\
& $\mathrm{~S}$ & 5 & $1.50 \pm 1.27$ & $0.66 \pm 0.70$ & $0.14 \pm 0.15$ & $1.21 \pm 2.28$ \\
\hline \multirow{5}{*}{ Cross } & $\mathrm{C}$ & 14 & $0.98 \pm 0.33$ & $0.50 \pm 0.18$ & $0.14 \pm 0.05$ & $-0.52 \pm 0.39$ \\
& MC & 106 & $2.15 \pm 0.92$ & $0.97 \pm 0.42$ & $0.29 \pm 0.12$ & $-0.22 \pm 0.16$ \\
& N & 80 & $2.64 \pm 0.92$ & $1.10 \pm 0.35$ & $0.34 \pm 0.13$ & $0.02 \pm 0.03$ \\
& MS & 94 & $1.27 \pm 0.42$ & $0.45 \pm 0.21$ & $0.12 \pm 0.05$ & $0.11 \pm 0.07$ \\
& $\mathrm{~S}$ & 19 & $0.96 \pm 0.24$ & $0.26 \pm 0.06$ & $0.05 \pm 0.01$ & $0.17 \pm 0.06$ \\
\hline
\end{tabular}

west toward the Willamette River or down the valley following the direction of the river, south to north.

The $0.8 \mathrm{~m}$ anemometer wind rose indicated that the channeled flow direction was between either $155^{\circ}$ and $215^{\circ}$ or $355^{\circ}$ and $15^{\circ}$. All periods with $\overline{w d}$ (the mean wind direction at $z=5 \mathrm{~m}$ ) within one of these ranges were considered to be periods of parallel flow and were used to determine standard profiles for parallel flow in the vineyard. All remaining periods were categorized as cross flow. Average meteorological statistics, including the streamwise velocity at $z=5 \mathrm{~m}$ as well as the velocity, friction velocity, and temperature scale at the canopy top for the periods in each of the five stability classes and two direction classes were determined (Tab. 2).

The microsphere release events were all performed when $\overline{w d}$ was between $346^{\circ}$ and $22^{\circ}$. Hence, they were categorized as having been done during times of parallel flow. Four of the release events were categorized as MC, one as N, and one as MS (see Tab. 3 in Sect. 4). For the remainder of the momentum analysis, only these three categories of parallel flow were considered.

Meteorological profiles for the MC, N, and MS categories showed that periods with MC stability exhibited different behavior than the MS periods (Fig. 6). The MC velocity profile had a shallower slope than the MS profile, but the two exhibited nearly equivalent downward momentum fluxes (Fig. 6A and 6B, respectively). These profiles are comparable to those reported in previous canopy studies (e.g., Aylor and Ferrandino, 1989; Finnigan, 2000; Dupont and Patton, 2012). The periods with a MC stability had higher temperatures near the ground and a steep decline (compared to the MS periods and the dry lapse rate) to $5 \mathrm{~m}$ while the MS periods had relatively low but uniform temperatures in the canopy with warmer air aloft (Fig. 6C). The N periods had behavior between the MC and MS periods.

The contrasting temperature slopes contributed to the MC periods exhibiting upward heat flux in and above the canopy, the MS periods exhibiting a downward flux over the same height range, and the $\mathrm{N}$ periods exhibiting mixed upward and downward fluxes (Fig. 6F). The erratic behavior of the $\mathrm{N}$ profile was attributed to a combination 

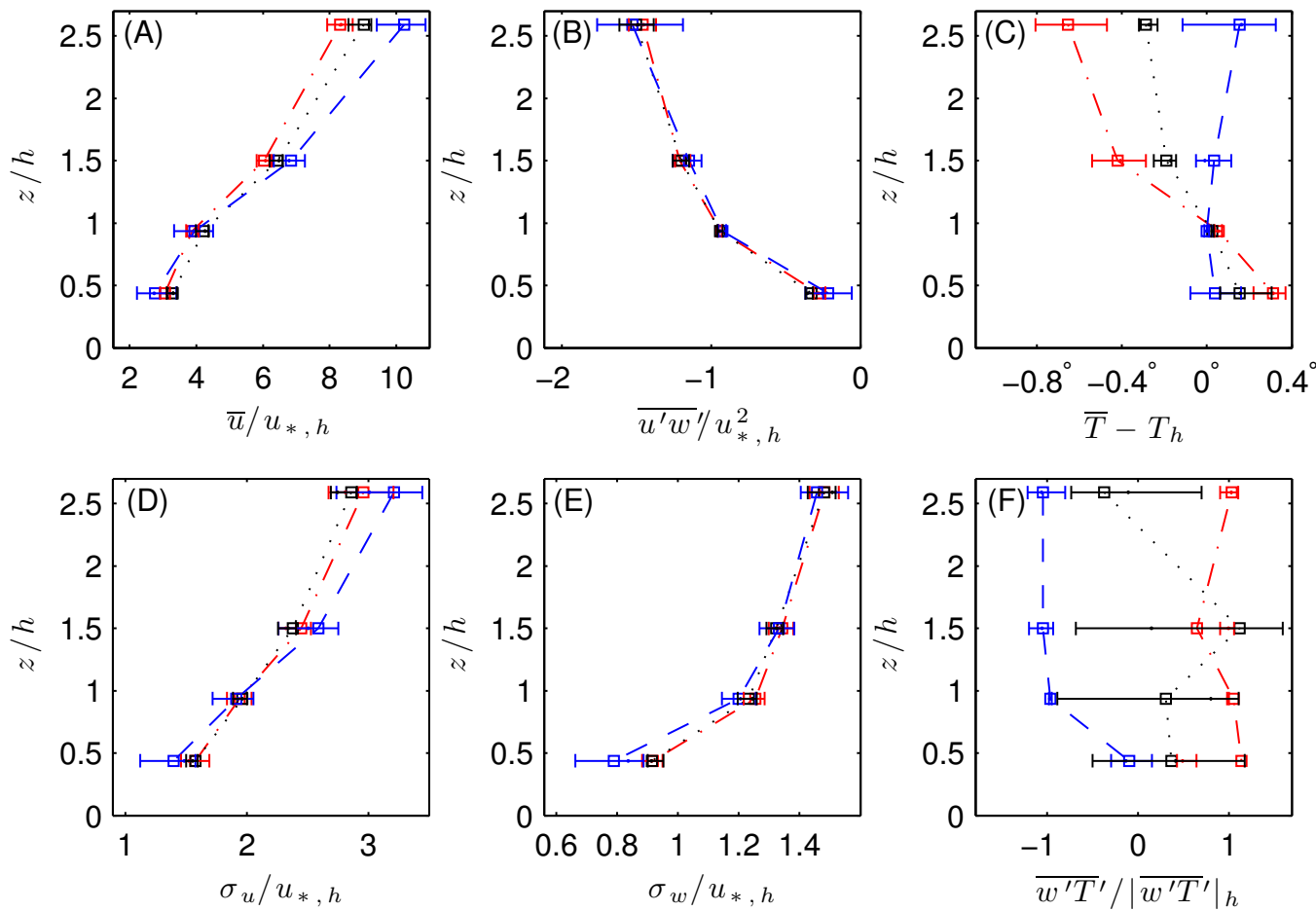

Figure 6: Mean profiles of the streamwise velocity (A), the vertical momentum flux (B), the temperature (C), the standard deviation of the streamwise velocity (D), the standard deviation of the vertical velocity (E), and the vertical heat flux (F). Variables are normalized using $u_{*, h}$ (Eq. 1), the temperature at the canopy top $\left(T_{h}\right)$, and the absolute values of the heat flux at the canopy top $\left(\left|\overline{w^{\prime} T_{s}^{\prime}}\right|_{h}\right)$. The MC periods are red with dot-dashed lines connecting the means $(\square)$. The $\mathrm{N}$ periods are black with dotted lines connecting the means. The MS periods are blue with dashed lines connecting the means. The errorbar ends show the $25^{\text {th }}$ and $75^{\text {th }}$ percentiles of the 30-minute periods in each category. The number of periods in each category are listed in Tab. 2 
of near-zero heat fluxes and the low number of $\mathrm{N}$ sampling periods. The observed near neutral temperature profile in the canopy for the MS periods (Fig. 6C) was likely caused by a heat flux convergence into the canopy. While the MC heat fluxes were approximately constant with height, the MS heat flux had a sharp decline in magnitude between the lowest two anemometer levels. Some MS periods even exhibited a positive heat flux at the mid-canopy, as depicted by the error-bars. The decline in the flux in the canopy suggested that relatively warm air was brought down into the canopy from above and was not transferred down through the canopy at the same rate. This same behavior was seen by Dupont and Patton (2012) in their study of a walnut canopy and can likely be explained by the sheltering effects of the canopy itself. During MS periods, typically seen around sunset, it was likely that due to the low energy storage capacity and the latent losses inherent in leaves, the canopy elements decreased in temperature much faster than did the ground. The ground, which had high energy storage capacity, negligible latent losses, and reduced convective losses (compared to ground with no canopy sheltering it), stayed warm for a longer period after sunset, resulting in a heat flux convergence over the height of the canopy. Urban canopy studies have also reported that the canopy sublayer often exhibits a near-neutral stability even when the larger scale forcing was non-neutral (e.g., Hanna et al., 2003).

The normalized velocity standard deviation profile shapes (Figs. 6D and 6E) were similar across the MC, N, and MS stability classes. The MS periods had the expected decrease in the magnitude of $\sigma_{u}$ and $\sigma_{w}$ compared to the the other classes, but this decrease is largely explained by $u_{*}$ and thus the profiles still collapsed for all of the stability classes. The collapse of the vertical momentum flux profiles and the velocity standard deviation profiles, in conjunction with the near neutral temperature profiles within the canopy, suggested that any decrease in mechanical mixing that would have been expected during MS periods (represented by $u_{*, h}$ or $\overline{u_{h}}$ ) was compensated for by the sensible heat flux convergence into the canopy. The result was nearly equivalent levels of mixing in the canopy regardless of stability.

\section{Dispersion Experiment Results}

Concentrations within each of the 12 microsphere plumes were sampled at 100 locations downwind of the source. This provided a relatively high resolution threedimensional representation of the near-source plume shape. Most previous dispersion studies in plant canopies sampled concentrations at considerably fewer locations and only along one axis or in one plane (e.g., Aylor and Ferrandino, 1989; Chamecki et al., 2012; Prussin et al., 2014). The few studies that have used three-dimensional arrays (e.g., Raynor et al., 1974; Gleicher et al., 2014) have been in relatively homogeneous and dense canopies and were not able to fully characterize the plume shape in the near-source region. The high-density three-dimensional array used here allowed for improved analyses of the plume shape with fewer a priori assumptions like those made by previous researchers including assumptions about plume spread in undersampled or unsampled coordinate directions, assumptions about flow or plume homogeneity, or assumptions about plume symmetry in the spanwise direction.

The mean meteorological conditions including values for $\bar{u}, \overline{u_{h}}, \delta, u_{*, h}$, and $h / L$ were determined for each of the six release events (Tab. 3). $\delta$ was defined as the difference between $\overline{w d}$ and the row direction (north to south). In this way, $\delta$ ranged between $-90^{\circ}$ and $90^{\circ}$ with $0^{\circ}$ indicating the wind direction was perfectly parallel to the vines, and $\pm 90^{\circ}$ meaning it was perfectly perpendicular. A negative $\delta$ represented winds 
Table 3: Table of the meteorological conditions determined during each release event including; $\bar{u}, \overline{u_{h}}, \delta$, $u_{*, h}$, and $h / L$

\begin{tabular}{cccccccc} 
Event & Date & Local Time & $\bar{u}(\mathrm{~m} / \mathrm{s})$ & $\overline{u_{h}}(\mathrm{~m} / \mathrm{s})$ & $\delta\left(^{\circ}\right)$ & $u_{*, h}(\mathrm{~m} / \mathrm{s})$ & $h / L$ \\
\hline \hline 1 & $9 / 28 / 11$ & $17: 15$ & 2.99 & 1.13 & 14.6 & 0.3315 & -0.0024 \\
\hline 2 & $9 / 28 / 11$ & $18: 28$ & 2.19 & 0.73 & -13.6 & 0.2150 & 0.0906 \\
\hline 3 & $9 / 30 / 11$ & $11: 04$ & 2.73 & 0.93 & 21.2 & 0.3610 & -0.0820 \\
\hline 4 & $9 / 30 / 11$ & $12: 55$ & 2.97 & 1.04 & 12.2 & 0.3651 & -0.0511 \\
\hline 5 & $10 / 13 / 11$ & $12: 01$ & 2.93 & 0.98 & 10.7 & 0.3366 & -0.0320 \\
\hline 6 & $10 / 13 / 11$ & $13: 41$ & 3.13 & 1.18 & -5.7 & 0.3602 & -0.0143 \\
\hline
\end{tabular}

from a counter-clockwise rotated direction compared to the vine row direction (westerly), and a positive $\delta$ represented winds from a clockwise rotated direction (easterly). All of the release events were conducted during afternoon hours when the winds were similar in speed and direction. The same statistics given in Tab. 3 were also calculated for 30-minute periods within which the release events were centered. In all six cases the values were nearly indistinguishable from the release period values, suggesting that the meteorological conditions were relatively steady during the events. The data necessary to create profiles of $\bar{u}, u_{*}, \sigma_{u}, \sigma_{v}, \sigma_{w}, \bar{T}$, and $\overline{w^{\prime} T^{\prime}}$ for each of the release events can be found in the Supplemental Material as Appendix B.

As an example of the plume shapes observed in the vineyard, the interpolated $\Pi$ $x-z$ planes for release event 5 are shown along with the $x-y$ planes at the impaction trap height just below $H_{r}$ (Fig. 7). The actual impaction trap data on the $x-y$ planes were included with the interpolated isolines. Impaction trap data were not included on the $x-z$ planes because no impaction traps landed exactly on that plane (Fig. 4). The highest $\Pi$ values were observed nearest to the source and decayed with height and in the downwind direction. This behavior compares well with what has been seen in many previous studies, specifically those with three-dimensional arrays in canopies (e.g., Raynor et al., 1974). It was observed that at larger downwind distances $(x>4 h)$ $\Pi$ approached a uniform distribution with height, especially within the canopy. This led to the signature of $H_{r}$ in the plume being less distinguishable. These same plume features have been reported in other studies (e.g., Huq and Franzese, 2013; Gleicher et al., 2014). The effect of microsphere settling was also identifiable in the $H_{r}=1.7 \mathrm{~m}$ plume from the decreasing height of the maximum $\Pi$ values with downwind distance. The channeling of the flow by the vine rows appeared to have caused the plume to also be channeled into the row direction. This was evidenced by the location of the maximum concentration traveling down the release aisle rather than in the mean wind direction. For release events 2 and 6 , when $\delta$ was $<0^{\circ}$ the plume centerline appeared to migrate from the release aisle to the neighboring aisle within $\approx 2 h$ downwind of the source (Figs. A3 and A9 of Appendix A of the Supplemental Material).

The three $y-z$ interpolation planes for release event 3 also showed the effect that $H_{r}$ had on the height of the plume centerline, especially near the source (Fig. 8). The plume shape's lack of dependence on $H_{r}$ at large downwind distances was manifested similarly to Fig. 7 in that at the $x=4.21 \mathrm{~h}$ planes the two plumes appeared very similar. The channeling of the plume by the canopy was again apparent as the maximum $\Pi$ value did not always occur at $y=0$ as would be expected if the canopy were not present. The plumes not included in Fig. 8 (Figs. A1-A10 of Appendix A of the 

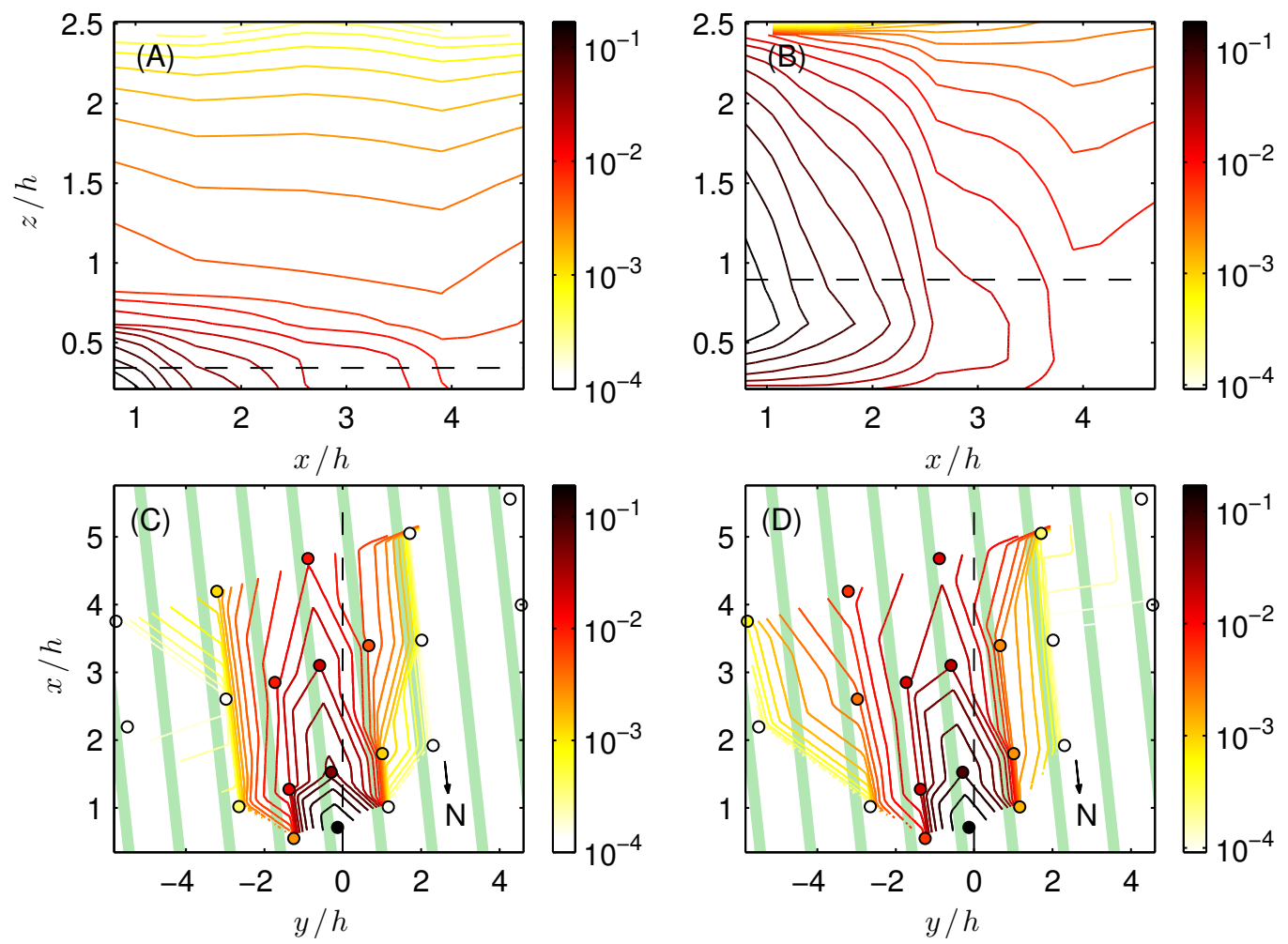

Figure 7: Scaled concentrations ( $\Pi$ ), on a logarithmic scale, from release event 5. (A) and (B) depict the interpolation onto the $x-z$ plane for the plumes with $H_{r}=0.7 \mathrm{~m}$ and $H_{r}=1.7 \mathrm{~m}$, respectively. The black dashed lines in (A) and (B) represent $H_{r}$ and the wind was from left to right. (C) and (D) depict the $x-y$ planes for the plume with $H_{r}=0.7 \mathrm{~m}$ and $H_{r}=1.7 \mathrm{~m}$, respectively, taken at the impaction trap height just below $H_{r}$. The isolines depict the interpolated data while the $\Pi$ values determined from the impaction traps at their respective locations are shown as the colored circles. The black dashed lines in (C) and (D) represent $\overline{w d}$, the wind is from bottom to top, and the green patches represent the vine rows. 

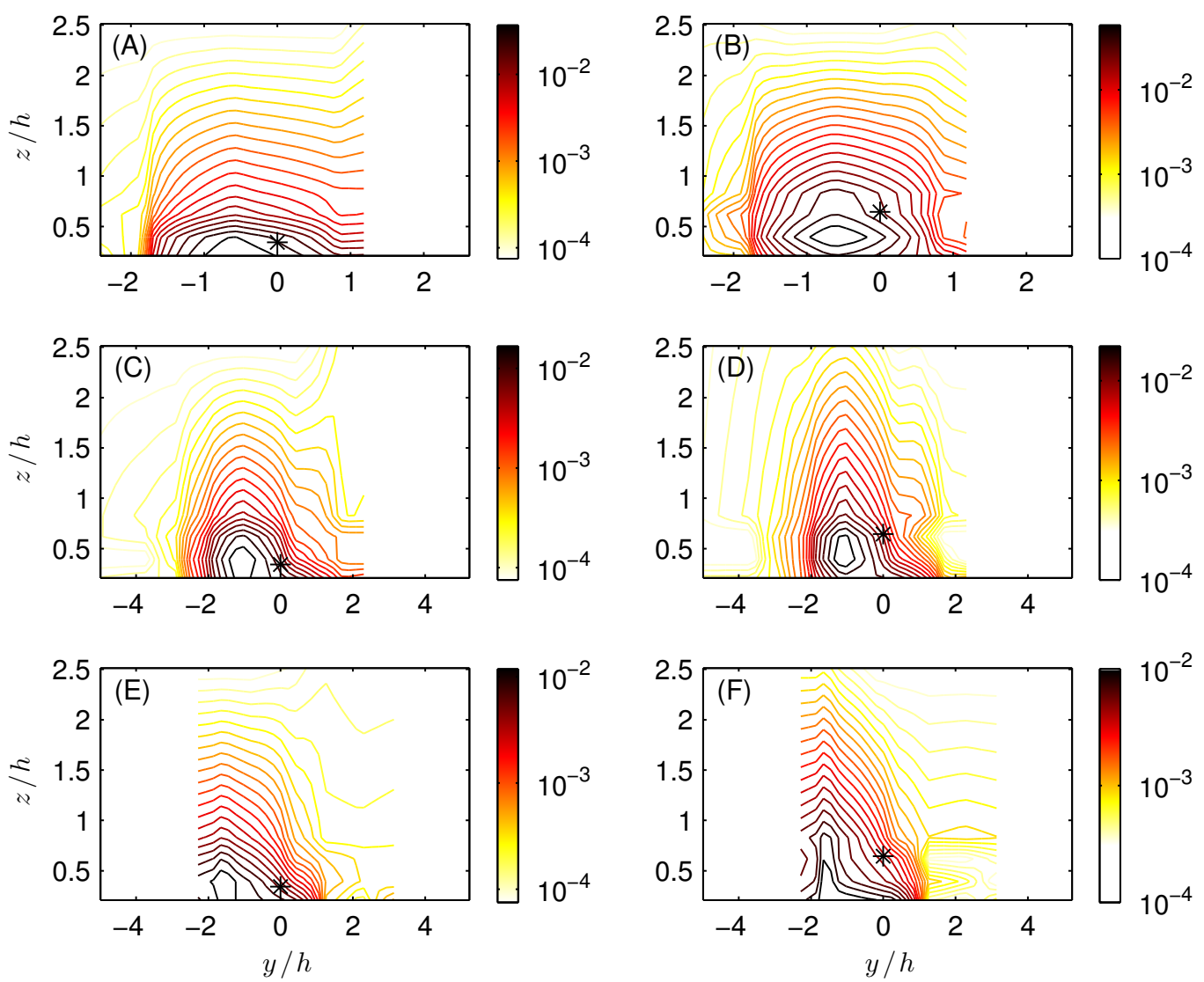

Figure 8: Scaled concentrations $(\Pi)$, on a log-scale, at the three downwind cross-wind interpolation planes as viewed from the source location looking along the $x$ axis for release event 3. (A), (C), and (E) depict the plume with $H_{r}=0.7 \mathrm{~m}$ while (B), (D), and (F) depict the plume with $H_{r}=1.7 \mathrm{~m}$. (A) and (B) are at $x=1.57 h,(\mathrm{C})$ and (D) are at $x=2.89 h$, and (E) and (F) are at $x=4.21 h$. The '* ' symbols depict the source location on the $x$ axis (i.e. at $H_{r}$ and $y=0$ ).

Supplemental Material) also exhibited this behavior and indicated that the impact of channeling was related to $\delta$, i.e., for larger $|\delta|$, the effect of the canopy on the plume was greater. This is similar to the channeling effects seen in Hoydysh and Dabberdt (1994) and Yee and Biltoft (2004) for urban flows where the maximum concentration was channeled down street canyons even when the upstream wind was not aligned with those canyons. The main difference between these urban examples and the vineyard is that the vineyard plume channeling is incomplete. It instead appeared to have features characteristic of both an urban channeled plume and of plumes typical of homogenous canopies or the atmospheric surface layer.

The channeling of the plume by the canopy also seemed to have led to the plume concentrations having a spanwise skewness directed from the aisle the plume was channeled down toward $\overline{w d}$. This was most easily observed in the difference in the concentration gradients in the spanwise direction on either side of the concentration maximum (e.g., Fig. 8(D)). It is possible to see a skewness in a spanwise profile of an otherwise 
non-skewed plume if the plane being studied is not truly orthogonal to the mean plume advection direction. To check that this was not the cause of the skewness seen in the interpolated data and because the in-canopy winds exhibited significant channeling into the row direction (Fig. 5), spanwise profiles taken orthogonally to the vine row direction were also investigated. Consistent behavior between spanwise profiles taken orthogonally to both $\overline{w d}$ and the vine row direction would indicate that the observed skewness was physical and not a function of studying a non-orthogonal plane of a nonskewed plume.

Data on planes taken orthogonally to the vine row direction were available from the uninterpolated impaction trap concentrations (Fig. 4). Individual spanwise profiles of $\Pi$ taken from those planes confirmed that a spanwise skewness $\left(\gamma_{y}\right)$ was indeed present in the plumes (Fig. 9). For the $H_{r}=1.7 \mathrm{~m}$ plume of release event $1\left(\delta>0^{\circ}\right)$, steeper gradients in the profiles were seen to the left of the release aisle and longer tails were seen to the right (toward $\overline{w d})$. The $H_{r}=1.7 \mathrm{~m}$ plumes from events 2 and $6\left(\delta<0^{\circ}\right)$ tended to have a steeper drop in the concentration to the right of the source and longer tails to the left of the release aisle (again toward $\overline{w d}$ ). Plumes not depicted in Fig. 9 exhibited similar behavior. Event 6 had the lowest $|\delta|$ and the most nearly symmetric spanwise profiles. A clear example of the skewness behavior of the plumes is depicted in Fig. 9(B) where the skewnesses for events 1 and 2 are approximately mirrored and the profile for event 6 is nearly symmetric. This again indicated that the plumes' shapes, and specifically $\gamma_{y}$, were related to $\delta$ and that as $|\delta|$ increased, so apparently did $\left|\gamma_{y}\right|$.

At the $x^{\prime}$ locations nearest to the source, the concentrations generally decreased with height below $H_{r}$. Similar behavior is reported in Aylor and Ferrandino (1989), Yee and Biltoft (2004), and Gleicher et al. (2014). As was observed in Fig. 7, at distances of $x^{\prime}>4 h$, the shape of any individual plume did not appear to change significantly as a function of the height within the canopy. This was specifically identifiable in the spanwise profiles for event 6 (Fig.9, subplots (C), (F), and (I)).

Variation in plume shape was apparent with increasing distance $x^{\prime}$ from the source. This included a clear decrease in the maximum concentrations and changes in $\gamma_{y}$. For event 2, $\gamma_{y}$ was negative within the canopy at the first two downwind distances even when the maximum concentration appeared to migrate one aisle to the left of the source (visible in the location of the peak in Fig. 9(B)). At the third $x^{\prime}$ distance however, $\gamma_{y}$ appeared to approach zero. This effect was likely due to turbulent mixing causing a general smoothing of the plume profiles.

The spanwise profiles for the impaction traps that were located above the canopy (not shown) exhibited more erratic behavior than was seen in the profiles in the canopy. The peak value in these profiles was typically seen at the impaction trap location nearest to the plume centerline defined by $\overline{w d}$. This suggested that because the channeling effects were not present in the freestream, the microspheres that escaped the canopy were typically advected along $\overline{w d}$.

A primary goal of this study was to elucidate the relationship between canopy architecture and plume shape characteristics. Specifically we desired to quantify the plume spread, the spanwise skewness, and the offset of the plume centerline from $\overline{w d}$. Plume spread quantification has been done by many previous researchers using a variety of techniques. Raynor et al. (1970) defined the plume width as the distance between the points on either side of the centerline where the concentration dropped to $10 \%$ of the centerline value. Others who had sufficient data density determined the spanwise standard deviation of the plume $\left(\sigma_{y}\right)$ by its statistical definition (e.g., Gryning et al., 1979; Peterson et al., 1999; Yee et al., 2006). Skelsey et al. (2008) and Prussin et al. (2014) 


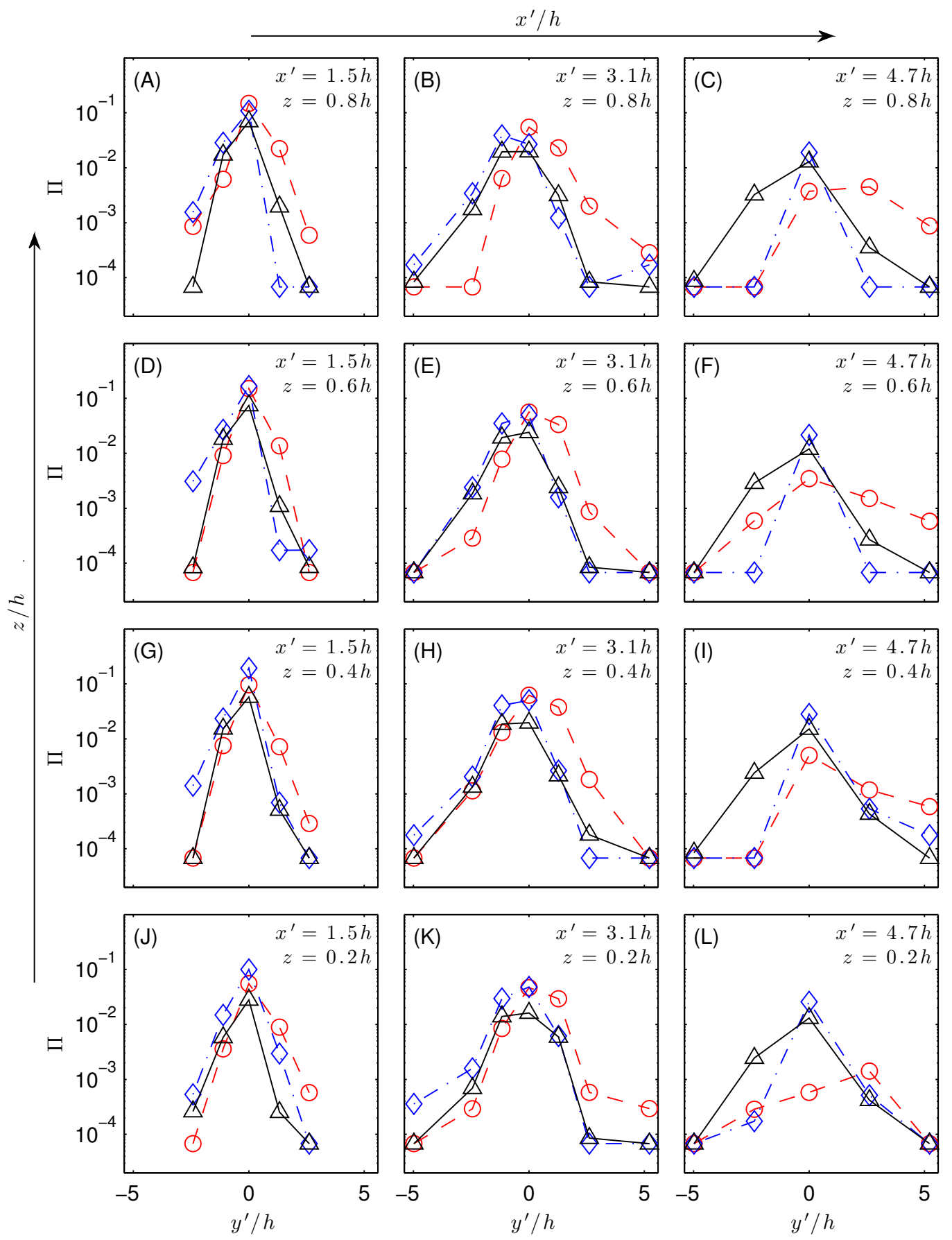

Figure 9: Spanwise profiles of the scaled concentrations (П) taken at three separate $x^{\prime}$ distances from the source for the $H_{r}=1.7 \mathrm{~m}$ plume from events 1, 2, and 6. (A), (B), and (C) depict data from the $1.6 \mathrm{~m}$ impaction traps; (D), $(\mathrm{E})$, and $(\mathrm{F})$ are from the $1.2 \mathrm{~m}$ impaction traps; $(\mathrm{G}),(\mathrm{H})$, and $(\mathrm{I})$ are from the 0.8 $\mathrm{m}$ impaction traps; and $(\mathrm{J}),(\mathrm{K})$, and $(\mathrm{L})$ are from the $0.4 \mathrm{~m}$ impaction traps. (A), (D), (G), and (J) are at $x^{\prime}=1.5 h ;(\mathrm{B}),(\mathrm{E}),(\mathrm{H})$, and $(\mathrm{K})$ are at $x^{\prime}=3.1 h$, and $(\mathrm{C}),(\mathrm{F}),(\mathrm{I})$, and $(\mathrm{L})$ are at $x^{\prime}=4.7 h$. The abscissa is the spanwise distance $\left(y^{\prime}\right)$ from the vine row direction normalized by the canopy height $(h)$. The data from event 1 is represented by a red dashed line, event 2 is represented by a blue dot-dashed line, and event 6 is depicted by a black solid line. Symbols for the three events are defined in Tab. 4. The concentration for impaction traps that collected zero microspheres was set to an arbitrary low value that was less than the traps' minimum detection limits so that an estimation of the concentration gradient could be visualized. 
tuned a combination of exponential, power, and Gaussian functions to field data in order to investigate the plumes' shapes. Perhaps the most common approach has been to fit a Gaussian distribution function to the spanwise and/or vertical profiles so that the standard deviations of the plume could be determined statistically from the fit (e.g., Yee and Biltoft, 2004; Venkatram et al., 2013; Huq and Franzese, 2013). Of those mentioned, only Skelsey et al. (2008) defined both $\sigma_{y}$ and the standard deviation of the plume in the vertical $\left(\sigma_{z}\right)$ simultaneously in a single formulation. One reason most others did not do this was that data was not available in both dimensions. None of the cited studies have attempted to quantify a skewness in the spanwise profiles. Because of the observed skewness in the spanwise profiles here (Figs. 7, 8, and 9), and the three-dimensionality of our array, we simultaneously defined $\sigma_{y}, \sigma_{z}$, and $\gamma_{y}$ through a single formulation.

The spanwise and vertical spread of the plume were determined by fitting a twodimensional modified Gaussian distribution to the data at each of the three $y-z$ interpolation planes. The skewness of the plumes was accounted for by including a skewness term in the Gaussian fit. The term was drawn from the Skew-Normal Distribution Function (SNDF) described in Azzalini (1985). The two-dimensional skewed Gaussian function that was fit to the data was,

$$
\begin{aligned}
\Pi= & \frac{A}{2 \pi \omega_{y} \sigma_{z}} \exp \left(\frac{-\left(y-\xi_{y}\right)^{2}}{2 \omega_{y}^{2}}\right)\left[1+\operatorname{erf}\left(\frac{\alpha_{y}\left(y-\xi_{y}\right)}{\omega_{y} \sqrt{2}}\right)\right] \\
& {\left[\exp \left(\frac{-\left(z-H_{e}\right)^{2}}{2 \sigma_{z}^{2}}\right)+\exp \left(\frac{-\left(z+H_{e}\right)^{2}}{2 \sigma_{z}^{2}}\right)\right], }
\end{aligned}
$$

where $A$ was a streamwise magnitude decay parameter, $\xi_{y}$ was a spanwise offset parameter used to account for channeling, $\alpha_{y}$ was the skewness parameter in the skewness term, and $H_{e}$ was the effective height of the plume source defined as $H_{e}=H_{r}-\Delta h$ (where $\Delta h$ was the distance the plume fell after exiting from the release device, analogous to the plume rise used in studies of buoyant plumes (Turner, 1994)). Because a skewness parameter was included, $\omega_{y}$ was used in place of the standard Gaussian standard deviation variable $\sigma_{y}$, but the two were related through the SNDF skewness parameter $\alpha_{y}$ as,

$$
\sigma_{y}=\sqrt{\omega_{y}^{2}\left(1-\frac{2 \alpha_{y}^{2}}{\pi\left(1+\alpha_{y}^{2}\right)}\right)} .
$$

The $y$ location of the mean of the SNDF and therefore of the spanwise concentration profile is related to the offset and skewness parameters as,

$$
\mu_{y}=\xi_{y}+\omega_{y} \alpha_{y} \sqrt{\frac{2}{\pi\left(1+\alpha_{y}^{2}\right)}} .
$$

If the spanwise skewness were zero then the location of the mean is equal to the offset parameter and also equal to the location of the maximum concentration in the spanwise profile. Unfortunately there is no analytical solution for the location of the maximum $\left(\mu_{y, \max }\right)$ in the SNDF. The statistical skewness of the spanwise profile, as taken from the SNDF is,

$$
\gamma_{y}=\left(2-\frac{\pi}{2}\right)\left(\frac{\left(2 \alpha_{y}^{2}\right)^{3 / 2}}{\left(\pi\left(1+\alpha_{y}^{2}\right)-2 \alpha_{y}^{2}\right)^{3 / 2}}\right) .
$$


Table 4: Table of the $\mathrm{r}^{2}$ values for the fit of Eq. 4 to the interpolated $\Pi$ data for each microsphere plume at each $y-z$ plane. $\mathrm{r}^{2}$ was defined as $1-\sum_{i}\left(\Pi_{o, i}-\Pi_{I, i}\right)^{2} / \sum_{i}\left(\Pi_{o, i}-\left\langle\Pi_{I}\right\rangle\right)^{2}$, where $\Pi_{o}$ values were from the optimized version of Eq. $4, \Pi_{I}$ were the interpolated values taken in the field, the subscript $i$ was for an individual index at one of the three $y-z$ planes, and \langle\rangle represented a mean taken over the plane. Symbols are specified for use in the Figs. 10 through 13.

\begin{tabular}{|c|c|c|c|c|c|}
\hline Release & Symbol & $H_{r}[\mathrm{~m}]$ & $x / h=1.57$ & $x / h=2.89$ & $x / h=4.21$ \\
\hline \multirow{2}{*}{1} & \multirow{2}{*}{0} & 1.7 & 0.994 & 0.976 & 0.888 \\
\hline & & 0.7 & 0.993 & 0.955 & 0.910 \\
\hline \multirow{2}{*}{2} & \multirow{2}{*}{$\diamond$} & 1.7 & 0.970 & 0.969 & 0.950 \\
\hline & & 0.7 & 0.969 & 0.976 & 0.945 \\
\hline \multirow{2}{*}{3} & \multirow{2}{*}{$x$} & 1.2 & 0.928 & 0.925 & 0.906 \\
\hline & & 0.7 & 0.986 & 0.967 & 0.963 \\
\hline \multirow{2}{*}{4} & \multirow[b]{2}{*}{$\square$} & 1.2 & 0.937 & 0.924 & 0.854 \\
\hline & & 0.7 & 0.933 & 0.897 & 0.820 \\
\hline \multirow{2}{*}{5} & \multirow{2}{*}{$*$} & 1.7 & 0.989 & 0.969 & 0.969 \\
\hline & & 0.7 & 0.993 & 0.982 & 0.958 \\
\hline \multirow{2}{*}{6} & \multirow{2}{*}{$\Delta$} & 1.7 & 0.992 & 0.986 & 0.977 \\
\hline & & 0.7 & 0.989 & 0.970 & 0.977 \\
\hline
\end{tabular}

Equation 4 was fit to the data by way of a multi-variable optimization performed in MATLAB (The MathWorks, Inc., version R2010a). The optimization employed the trust-region approach described in Coleman and $\mathrm{Li}$ (1996). This included solving for $A, \sigma_{z}, \omega_{y}, \xi_{y}, \alpha_{y}$, and $\Delta h$ at each of the three interpolated $y-z$ planes. For each of the plumes, a minimum of 115 interpolated points were used on each of the three $y-z$ planes. Increases in the interpolation resolution resulted in minimal variation in the values of the shape parameters.

It is important to note that due to the discrete nature of the canopy architecture and the low spanwise spatial resolution of the array relative to the architecture, Eq. 4 should not be perceived as an exact instantaneous representation of the spanwise concentration profile but instead as a tool to estimate average plume spread parameters. Equation 4 was found to fit the field data very accurately (Tab. 4) thus giving credence to use of the statistics of the fit for plume shape investigation.

The values for $\sigma_{y}$ and $\sigma_{z}$ determined for each of the plumes through the multivariable optimization were the first to be examined. They were non-dimensionalized by spanwise and vertical length scales $L_{y}$ and $L_{z}$, respectively, and plotted as functions of a flight time scale $t=x / \overline{u_{h}}$ normalized by spanwise and vertical Lagrangian turbulent timescales defined as $T_{y}=L_{y} / \sigma_{v}$ and $T_{z}=L_{z} / \sigma_{w}$, respectively, where $\sigma_{v}$ is the standard deviation of the spanwise velocity (Fig. 10). The turbulent timescales were meant to approximate the horizontal and vertical decorrelation timescales in the canopy and therefore velocity data from the canopy top were used (Tab. 3). These relations were used in Huq and Franzese (2013) and are analogous to those used by others for approximating deccorrelation time scales at the middle of the atmospheric boundary layer (e.g., Hanna, 1981; Degrazia et al., 2001). $L_{y}$ was set equal to $r_{s} / 2$ and $L_{z}$ to the canopy height $h$ (Castro et al., 2006).

As the plumes were advected downwind the widths and heights tended to increase. Some correlation was observed between the smoothness of the increase and the quality of the curve fit to the data (Tab. 4). The plumes for which the curve fit approach 
best matched the data showed the smoothest and most consistent growth. The more sporadic lines may have been caused by the shortcomings of the curve fit and not the physics of those plumes. The significant spread of the $\sigma_{z}$ values found here is partially attributed to poor concentration resolution near the ground. Particularly for the plumes with $H_{r}=0.7 \mathrm{~m}$, when Eq. 4 was fit to the data, a high level of uncertainty was seen in $\sigma_{z}$ because the maximum $\Pi$ was typically seen at the lowest impaction traps and no information was available below $40 \mathrm{~cm}$.

There was no obvious trend observed based on the atmospheric stability at the time of the event. This was attributed to the near-constant level of mixing in the canopy regardless of the stability class (Sect. 3).

For comparison, the $\sigma_{y}$ values for all 12 plumes were plotted along with the relationship used by Franzese and Huq (2011). This relationship, derived from the theory of Taylor (1921) for use in estimating plume spread when $t \approx T_{y}$, was,

$$
\sigma_{y}^{2}=\sigma_{y 0}^{2}+2 L_{y}^{2}\left(\exp \left(\frac{-t}{T_{y}}\right)+\frac{t}{T_{y}}-1\right),
$$

where $\sigma_{y 0}$ was the spanwise standard deviation of the plume at the point source (Fig. 10A). The plume spread at the source has been shown to be governed by multiple mechanisms (Allwine et al., 2002) and has been related to the relevant scales of the surrounding canopy obstacles (Hanna et al., 2003; Hanna and Baja, 2009). The formulation is shown using $\sigma_{y 0}=h / 2$ which was recommended by Hanna et al. (2003) for urban canopies. The behavior of $\sigma_{z}$ was compared to,

$$
\sigma_{z}^{2}=\sigma_{z 0}^{2}+\frac{b^{2} t^{2} L_{z}^{2}}{T_{z}^{2}}
$$

where $b$ was an empirical constant and $\sigma_{z 0}$ was the vertical standard deviation of the plume at the point source. This relationship was used in Franzese and Huq (2011) and Huq and Franzese (2013) and was derived based on Hunt and Weber (1979). Franzese and Huq (2011) reported that values for $b$ of 1.0 and 0.5 worked well for daytime and nighttime conditions, respectively. Equation 9 with both $b$ values is shown (Fig. 10B) with $\sigma_{z 0}=0$ for both formulations. The Pasquill-Gifford formulation for vertical plume spread under Pasquill's class C stability regime was also included for comparison (Turner, 1994). Class C was used because five of the six release events were performed under MC stability. The Pasquill-Gifford formulation does not include a non-zero initial plume spread and is only applicable for larger transport distances. Neither Eq. 9 nor the Pasquill-Gifford formulation was developed specifically for application to spread within plant canopies, but they approximately covered the range of values and slopes observed in the data. A value of $b=0.5$ appeared to produce the closest fit to the average of the field data regardless of the stability class of the release event.

It was observed that due to the channeling of the plume within the canopy aisles, the spanwise location of the maximum concentration followed the row direction and therefore, through simple geometry, was offset from $\overline{w d}$ following,

$$
\mu_{y, \max }=-x \tan (\delta) .
$$

After fitting Eq. 4 to each $y-z$ plane of each of the plumes, the spanwise locations of the maximum concentrations were determined numerically. The impaction trap array (Fig. 4) included only one row of trap towers in each aisle and as a result, $\mu_{y, \text { max }}$ could 

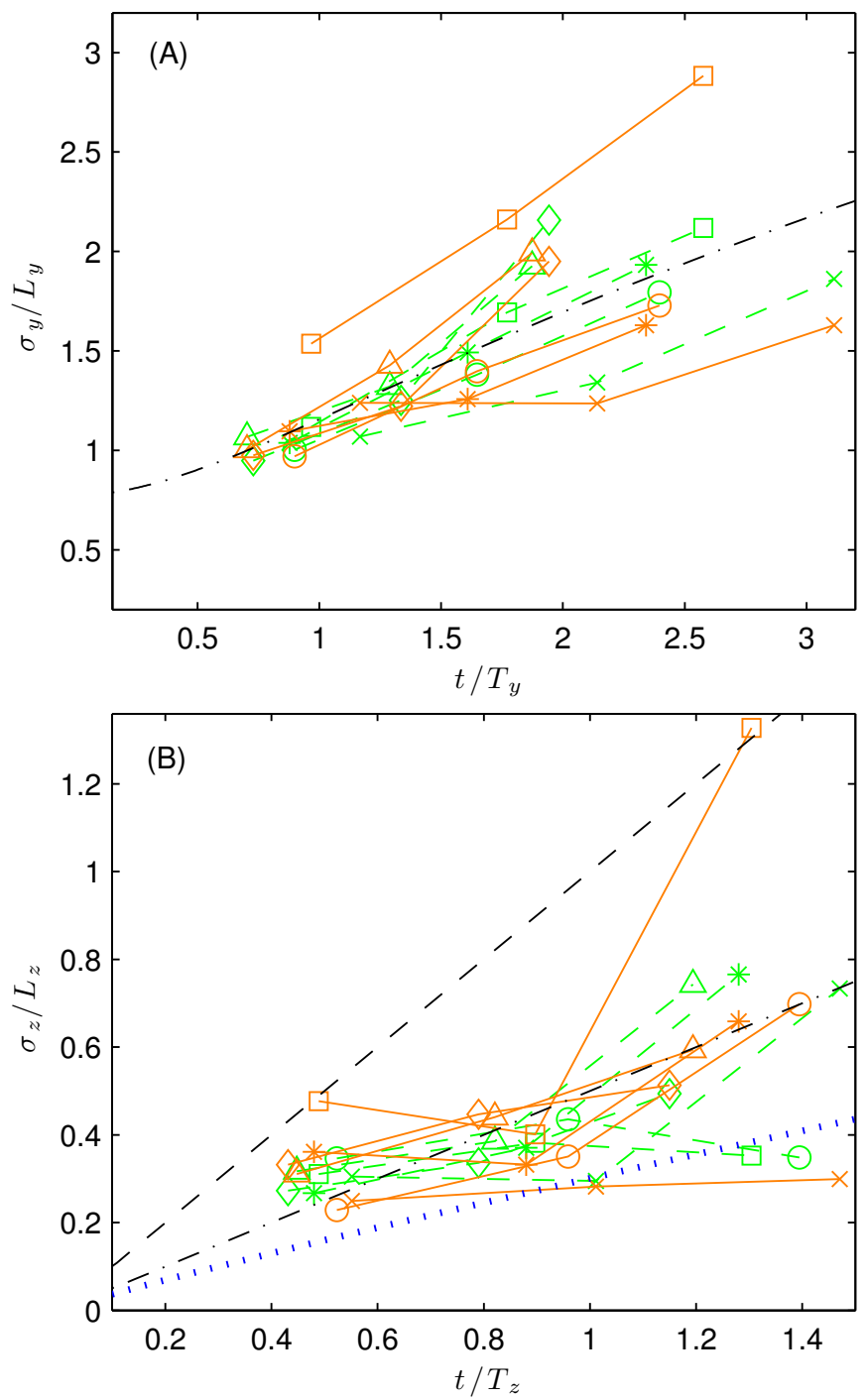

Figure 10: The standard deviations of the plumes, $\sigma_{y}(\mathrm{~A})$ and $\sigma_{z}(\mathrm{~B})$, as well as estimates from formulations found in the literature. Plumes with $H_{r} \geqslant 1.2 \mathrm{~m}$ and $H_{r}=0.7 \mathrm{~m}$ are represented as green and orange symbols (Tab. 4) with dashed and solid lines, respectively. The black dot-dashed line in (A) represents Eq 8 with $\sigma_{y 0}=h / 2 \mathrm{~m}$. The black lines in (B) represent Eq. 9 with the dashed line using $b=1.0$ and the dot-dashed line using $b=0.5$, both with $\sigma_{z 0}=0 \mathrm{~m}$. The blue dotted line represents the Pasquill-Gifford formulation for plume spread under Pasquill's class $\mathrm{C}$ stability. 


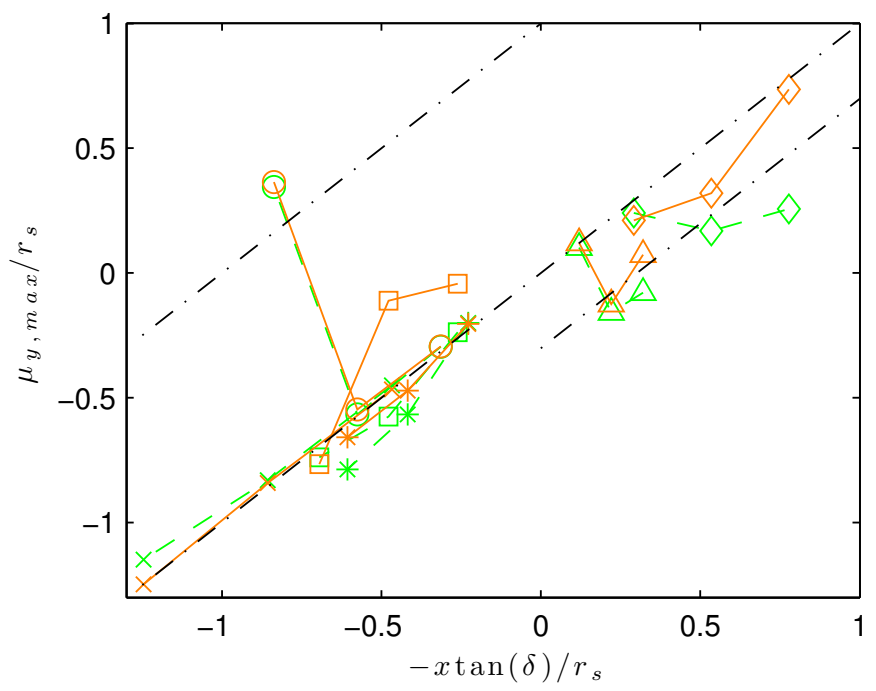

Figure 11: The location of the numerically determined maximum $\Pi$ in each plume as a function of the downwind distance and the wind direction. Plumes with $H_{r} \geqslant 1.2 \mathrm{~m}$ and $H_{r}=0.7 \mathrm{~m}$ are represented as green and orange symbols (Tab. 4) with dashed and solid lines, respectively. The black dot-dashed lines represent Eq. 10 with offsets included to account for when the plume centerline migrated to a neighboring aisle.

only be reliably determined to an accuracy of which aisle it was contained in. It was possible that the maximum concentration could have existed at a different spanwise location within the aisle than where the impaction trap was located, and though such a variation could not be known or recreated from the collected data, it would not change the conclusion here that the maximum was always channeled along the aisle of the source. Additionally, there were a few cases where the plume centerline appeared to migrate from the release aisle to one of the neighboring aisles at some distance downwind of the source (Fig. A9). After initially being channeled down the release aisle, enough microspheres were able to migrate to a neighboring aisle that the location of maximum concentration also moved over. When the plume centerline moved one aisle to the west of the source aisle, $\mu_{y, \text { max }}$ increased by $\approx 1.0 r_{s}$, the upper line in Fig. 11. Such a migration of the centerline was possible when $\delta>0$ and was more likely to occur as $|x \tan (\delta)|$ increased. We hypothesize that such a movement of the plume centerline is almost certain when $|x \tan (\delta)|>r_{s}$ but more experimentation is needed to test this. When the plume centerline moved one aisle to the east, during events with $\delta<0, \mu_{y, \text { max }}$ decreased by $\approx 0.3 r_{s}$. This was different from the events when $\delta>0$ because the release device was not centered in the aisle and a smaller change in $\mu_{y, \max }$ was sufficient for the plume center to change aisles (Figs. A3 and A9 of Appendix A of the Supplemental Material). This is depicted as the lowest of the three black dot-dashed lines in Fig. 11.

In nearly two-thirds of the pairs of $\mu_{y}$ and $\mu_{y, \max }$ values determined from the multivariable optimization (12 plumes $\times 3 x$ distances), $\left|\mu_{y}\right|<\left|\mu_{y, \max }\right|$ so that the location of $\mu_{y}$ was closer to $\overline{w d}$ than was $\mu_{y, \max }$. An approximation of $\mu_{y}=2 \mu_{y, \max } / 3$ was determined using a linear regression of all of the pairs where $\left|\mu_{y}\right|<\left|\mu_{y, \max }\right|$. In four of the pairs where $\left|\mu_{y}\right|>\left|\mu_{y, \max }\right|$, the plume appeared to have migrated to the neighboring 
aisle after $\mu_{y, \max }$ exceeded $0.3 r_{s}$ with $\delta<0$.

By definition, the skewness of the SNDF is related to the percentage of the standard deviation that is skewed to one side of $\mu_{y}$. This also meant that $\mu_{y, \max }$ and the skewness were not independent variables and that some relationship must exist between them. Based on these definitions we expected that $\gamma_{y}$ would be related to $\left(\mu_{y}-\mu_{y, \max }\right) / \sigma_{y}$. However, because no analytical solution exists for $\mu_{y, \text { max }}$ in the SNDF, none can exist for this relationship either. The values for $\gamma_{y}$ were plotted against $\left(\mu_{y}-\mu_{y, \max }\right) / \sigma_{y}$ determined for each of the plumes (Fig. 12). An estimation of the relationship between the variables defined by,

$$
\gamma_{y}=\operatorname{erf}\left(\frac{\pi\left(\mu_{y}-\mu_{y, \max }\right)}{2 \sigma_{y}}\right)
$$

was determined to match the data exceptionally well. Using a simple random number generation approach, the maximum absolute error that this estimation produced when compared to the optimized $\gamma_{y}$ values was only 0.02. Typically for the events where $\delta>$ $0, \mu_{y, \max }<\mu_{y}<0$. This resulted in $\gamma_{y}>0$, meaning that the spanwise concentration profile was skewed from the location of $\mu_{y, \max }$ toward the axis of $\overline{w d}$, i.e., in Fig. 8 , the gradient on the $\overline{w d}$ side of $\mu_{y, \max }$ (right) was more shallow than the gradient to the left of $\mu_{y, \max }$. For events with $\delta>0$, the opposite effect was typical. We hypothesize that this behavior was caused by the directional shear stress caused by the difference in the channeled wind direction and the mean direction of the forcing $(\overline{w d})$. More specifically, that while the bulk of the plume is channeled along the aisle it was released in, the plume is pressed in the direction of $\overline{w d}$ and some portion of the microspheres are able to migrate into neighboring aisles leading to the longer tail in the spanwise profile pointing from the release aisle back toward $\overline{w d}$. This behavior was altered when the plume center migrated to a neighboring aisle but may likely repeat itself by way of the plume becoming channeled in that aisle while still being pressed towards $\overline{w d}$.

As explained previously, the parameter $\Delta h$ was the distance that the plume fell below the source height and therefore controls the height of the plume centerline. Due to the limited resolution in the vertical direction, especially in the lower canopy, the values obtained for $\Delta h$ from the multi-variable optimization procedure had a high degree of uncertainty. This was most pronounced for the events where $H_{r}=0.7 \mathrm{~m}$. Plumes with $H_{r} \geqslant 1.2 \mathrm{~m}$ had multiple impaction trap heights below the plume source and so were considered to be more reliable for the determination of $\Delta h$. A linear regression performed on the $18 \Delta h$ values from these events (6 events $\times 3 x$ distances) yielded,

$$
\Delta h=0.30+0.039 \frac{x}{u_{h}} .
$$

This equation was an interesting result as the slope term had units of velocity and had a value nearly indistinguishable from the expected settling velocity of the microspheres, i.e., $3.9 \mathrm{~cm} / \mathrm{s}$. A similar relationship was suggested in Okubo and Levin (1989) to account for the downward trajectory of the centerline of heavy-particle plumes. The intercept value of $30 \mathrm{~cm}$ was likely an initial fall distance of the plume at the source, analogous to the initial plume rise used in studies of buoyant plumes (Turner, 1994).

The plume concentration multiplier $A$ was used to scale the values determined by Eq. 4 to match the values collected in the field. A value of 1.0 would suggest that $A$ could be removed from Eq. 4 and all of the released mass would have still been accurately accounted for. For all but one of the experimental plumes, $A$ was $<1.0 \mathrm{sug}$ gesting that mass was removed from the plumes and not accounted for by the spread 


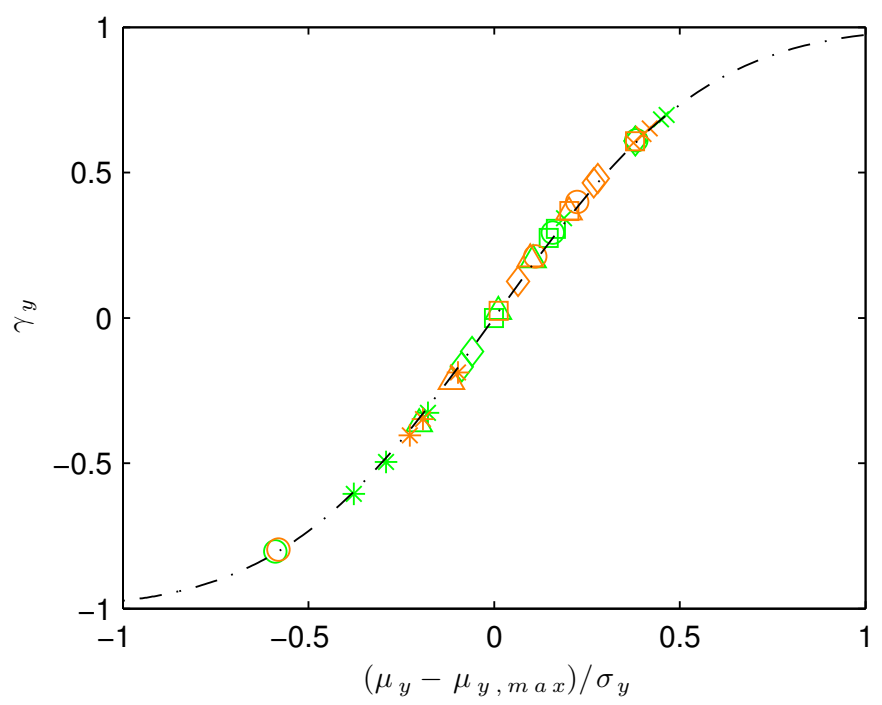

Figure 12: The relationship between the skewness of the SNDF and the other statistical parameters. Plumes with $H_{r} \geqslant 1.2 \mathrm{~m}$ and $H_{r}=0.7 \mathrm{~m}$ are represented as green and orange symbols (Tab. 4), respectively. The black dot-dashed line represents Eq. 11.

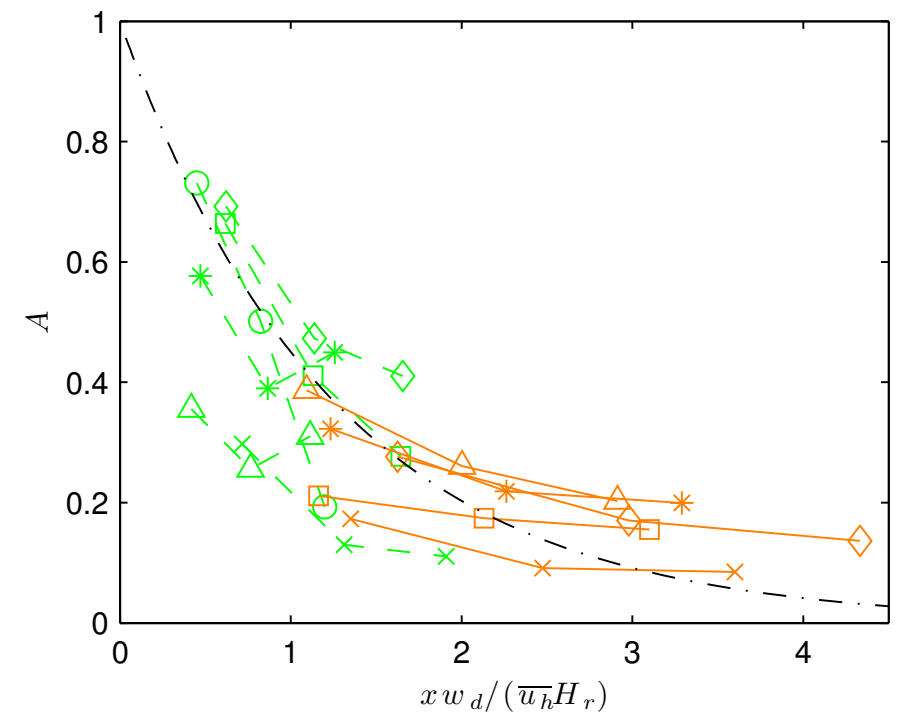

Figure 13: The multiplier, $A$, needed to scale the modeled $\Pi$ values. Plumes with $H_{r} \geqslant 1.2 \mathrm{~m}$ and $H_{r}=0.7$ $\mathrm{m}$ are represented as green and orange symbols (Tab. 4) with dashed and solid lines, respectively. The black dot-dashed line represents Eq. 13. 
alone (Fig. 13). The remaining plume ( $H_{r}=0.7$ during the first event) was excluded from this analysis as it had values of $A>1.0$ suggesting that the amount of mass actually released was more than was recorded in the field. It is important to note that the value of $A$ only impacts the concentration magnitudes and does not affect the parameters that define the plume shape (e.g., $\sigma_{y}, \gamma_{y}$ ). Physically, $A$ represented multiple processes in the canopy which worked to deplete the number of spheres in the plume. These processes include deposition onto the plant elements and ground by settling and impaction. Models have been proposed to explain the processes controlling this depletion (e.g., Aylor and Sutton, 1992; Raupach et al., 2001; Pardyjak et al., 2008; Skelsey et al., 2008; Chamecki et al., 2012). We did not investigate these processes in depth here, but simply compared the depletion of microspheres that was observed in the field to,

$$
A=\exp \left(-\sqrt{\frac{2}{\pi}} \frac{x w_{d}}{\overline{u_{h}} H_{r}}\right),
$$

where $w_{d}$ is the total deposition velocity of microspheres to both the ground and the vegetation. A least-squares regression found that $w_{d}=0.36 \mathrm{~m} / \mathrm{s}$ was best for our data. Aylor (1978) and Aylor and Sutton (1992) used a very similar relationship with $\sigma_{z}$ in place of $H_{r}$. Equation 13 tended to match the values determined for the depletion of microspheres from the plume in the field reasonably well.

\section{Final Conclusions}

Analysis of the momentum data from the vineyard field experiment showed that the canopy's impact on turbulence statistics taken during parallel flow did not differ significantly from that seen in other canopy studies. The architecture did however significantly effect the wind direction within the canopy which resulted in turning of the velocity profile when the winds were not aligned with the vine rows. It was also observed that the total level of mixing in the canopy was maintained by a heat flux convergence even when increasing stability would have caused the mechanical mixing of the flow to decrease. The canopy architecture of a vineyard was found to cause the microsphere plumes to be channeled down the aisles but skewed back toward the mean wind direction. From this we can conclude that the vine row direction is arguably the most important parameter for estimating plume shape. The shape of the plume was studied by fitting a simple bi-directional Gaussian distribution to the field data at three independent downwind distances from the plume source. The statistics from these fits were able to demonstrate the channeling of the plume into the vine row direction by way of an offset parameter that tracked the plume centerline. The skewed nature of the plume was also measured using a skewness term drawn from the SNDF. It is unclear at this time if these same effects would be seen for larger values of $\delta$. Future experiments need to be conducted when $22^{\circ}<\delta<90^{\circ}$. Release events where collection is performed at much larger downwind length scales should also be conducted. We hypothesize that for longer distance transport the near-source effects of the canopy would diminish and the relationships between the architecture and the values of $\mu_{y}$ and $\mu_{y, \max }$ would be altered. All of the statistical parameters of the plume were compared to published functions of simple meteorological and canopy architectural variables. To solidify our understanding of these relationships and improve our confidence in the plume behavior near the ground, experiments with a wider range of meteorological conditions and with the lowest impaction traps closer to the ground are needed. Finally, we believe that in future modeling efforts on dispersion within canopies, and especially 
those composed of discrete elements, definitions of canopy architecture need to exist in the models. Simply using a homogeneous canopy density analogy will never be able to reproduce results like the spanwise skewness observed here.

\section{Acknowledgments}

This work was funded by the United States Department of Agriculture (USDA) project 5358-22000-039-00D, the National Science Foundation grant AGS 1255662, and the University of Utah's Global Change and Sustainability Center. We thank Cole Provence, Jim Eynard, Andy Albrecht, Jessica Keune, and Tom Loveday for their excellent assistance with the field campaign. The use trade, firm, or corporation names in this publication are for information and convenience of the reader. Such use does not constitute an endorsement or approval by the USDA or the Agriculture Research Service of any product or service to the exclusion of others that may be suitable.

\section{References}

Addepalli B, Pardyjak ER. 2013. Investigation of the flow structure in step-up street canyons - mean flow and turbulence statistics. Boundary-Layer Meteorol. 148: 133155 .

Allwine KJ, Shinn JH, Streit GE, Clawson KL, Brown M. 2002. Overview of Urban 2000: A multiscale field study of dispersion through an urban environment. Bull. Amer. Meteor. Soc. 83: 521-536.

Aylor DE. 1978. Dispersal in time and space: Aerial pathogens. In JG Horsfall and EB Cowling (Eds.), Plant Disease: An Advanced Tretise. Vol. 2. Academic Press: New York, pp. 159-180.

Aylor DE, Ferrandino FJ. 1989. Dispersion of spores released from an elevated line source within a wheat canopy. Boundary-Layer Meteorol. 46: 251-273.

Aylor DE, Flesch TK. 2001. Estimating spore release rates using a lagrangian stochastic simulation model. J. Appl. Meteor. 40: 1196-1208.

Aylor DE, Fry WH, Mayton H, Andrade-Piedra JL. 2001. Quantifying the rate of release and escape of Phytophthora infestans sporangia from a potato canopy. Phytopathology 91: 1189-1196.

Aylor DE, Sutton TB. 1992. Release of Venturia inaequalis ascospores during unsteady rain: Relationship to spore transport and deposition. Phytopathology 82: 532-540.

Azzalini A. 1985. A class of distributions which includes the normal ones. Scand. J. Statist. 12(2): 171-178.

Bailey B, Stoll R. 2013. Turbulence in sparse, organized vegetative canopies: A largeeddy simulation study. Boundary-Layer Meteorol. 147: 369-400.

Bailey BN, Stoll R, Pardyjak ER, Mahaffee WF. 2014. Effect of vegetative canopy architecture on vertical transport of massless particles. Atmos. Env. 95: 480-489.

Belcher SE. 2005. Mixing and transport in urban areas. Phil. Trans. R. Soc. A 363: 2947-2968. 
Böhm M, Finnigan JJ, Raupach MR, Hughes D. 2013. Turbulence structure within and above a canopy of bluff elements. Boundary-Layer Meteorol. 146: 393-419.

Bouvet T, Wilson JD, Tuzet A. 2006. Observation and modeling of heavy particle deposition in a windbreak flow. J. Appl. Meteorol. Climatol. 45: 1332-1349.

Braun U. 1995. The powdery mildews (Erysiphales) of europe. Gustav Fischer Verlag: New York. p. 337.

Cassiani M, Katul GG, Alberston JD. 2008. The effects of canopy leaf area index on airflow across forest edges: Large-eddy simulation and analytical results. BoundaryLayer Meteorol. 126: 433-460.

Castro IP, Cheng H, Reynolds R. 2006. Turbulence over urban-type roughness: Deduction from wind-tunnel measurements. Boundary-Layer Meteorol. 118: 109-131.

Chamberlain AC. 1975. The movement of particles in plant communities. In JL Monteith (Eds.), Vegetation and the Atmosphere. I. Principles. Academic Press: New York, pp. 155-203.

Chamecki M, Default NS, Isard SA. 2012. Atmospheric dispersion of wheat rust spores: A new theoretical framework to interpret field data and estimate downwind dispersion. J. Appl. Meteorol. Climatol. 51: 672-685.

Coleman TF, Li Y. 1996. An interior trust region approach for nonlinear minimization subject to bounds. SIAM J. Optimization 6: 418-445.

Davis JM, Eisner AD, Wiener RW, Main CE. 1997. A flow visualization study of spore release using a wind tunnel-mounted laser light sheet. Plant Dis. 81: 1057-1065.

Degrazia GA, Campos CRJ, Carvalho JC, Anfossi D, Goulart AG. 2001. Turbulence parameterisation for Lagrangian stochastic dispersion models. Revista Brasileira de Meteorol. 16(2): 123-134.

Detto M, Katul GG, Siqueira M, Juang JY, Stoy P. 2008. The structure of turbulence near a tall forest edge: The backward-facing step flow analogy revisited. Ecological Applications 18: 1420-1435.

Dupont S, Brunet Y. 2008. Influence of foliar density profile on canopy flow: A largeeddy simulation study. Agric. For. Meteorol. 148: 976-990.

Dupont S, Patton EG. 2012. Influence of stability and seasonal canopy changes on micrometeorology within and above an orchard canopy: The CHATS experiment. Agric. For. Meteorol. 157: 11-29.

Dwyer MJ, Patton EG, Shaw RH. 1997. Turbulent kinetic energy budgets from a largeeddy simulation of airflow above and within a forest canopy. Boundary-Layer Meteorol. 84: $23-43$.

Ferrandino FJ. 1993. Dispersive epidemic waves: I. Focus expansion within a linear planting. Phytopathology 83: 795-802.

Finnigan JJ. 2000. Turbulence in plant canopies. Ann. Rev. Fluid Mech. 32: 519-571.

Franzese P, Huq P. 2011. Urban dispersion modelling and experiments in the daytime and nighttime atmosphere. Boundary-Layer Meteorol. 139: 395-409. 
Gleicher SC, Chamecki M, Isard SA, Pan Y, Katul GG. 2014. Interpreting threedimensional spore concentration measurements and escape fraction in a crop canopy using a coupled Eulerian?Lagrangian stochastic model. Agric. For. Meteorol. 194: $118-131$.

Gregory PH. 1973. The microbiology of the atmosphere. Leonard Hill Books: London. p. 377.

Gryning SE, Lyck E, Hedegaard K. 1979. Short-range diffusion experiments in unstable conditions over inhomogeneous terrain. Tellus. 30: 392-403.

Hage KD. 1961. On the dispersion of large particles from a 15-m source in the atmosphere. J. Meteorol. 18: 534-539.

Hanna SR. 1981. Lagrangian and Eulerian time-scale relations in the daytime boundary layer. J. App. Meteorol. 20: 242-249.

Hanna SR, Britter R, Franzese P. 2003. A baseline urban dispersion model evaluated with Salt Lake City and Los Angeles tracer data. Atmos. Environ. 37: 5069-5082.

Hanna SR, Baja E. 2009. A simple urban dispersion model tested with tracer data from oklahoma city and manhattan. Atmos. Environ. 43: 778-786.

Hoydysh WG, Dabberdt WF. 1994. Concentration fields at urban intersections: Fluid modeling studies. Atmos. Environ. 28: 1849-1860

Huang J, Cassiani M, Albertson JD. 2009. The effects of vegetation density on coherent turbulent structures within the canopy sublayer: A large-eddy simulation study. Boundary-Layer Meteorol. 133: 253-275.

Hunt JCR, Weber AH. 1979. A Lagrangian statistical analysis of diffusion from a ground-level source in a turbulent boundary layer. Quart. J. Roy. Meteorol. Soc. 105: 423-443

Huq P, Franzese P. 2013. Measurements of turbulence and dispersion in three idealized urban canopies with different aspect ratios and comparisons with a gaussian plume model. Boundary-Layer Meteorol. 147: 103-121.

Jarvis WR. 1977. Botryotinia and Botrytis species: Taxonomy, physiology, and pathogenicity. a guide to the literature. Research Branch, Canada Department of Agriculture: Harrow, Ontario, p. 195.

Johnson LF, Roczen DE, Youkhana SK, Nemani RR, Bosch DF. 2003. Mapping vineyard leaf area with multispectral satellite imagery. Comput. Electron. Agric. 38: 33 44

Judd MJ, Raupach MR, Finnigan JJ. 1996. A wind tunnel study of turbulent flow around single and multiple windbreaks, Part I: Velocity fields. Boundary-Layer Meteorol. 80: 127-165.

Klein EK, Lavigne C, Foueillassar X, Gouyon P-H, Larédo C. 2003. Corn pollen dispersal: Quasi-mechanistic models and field experiments. Ecol. Monogr. 73: 131150 . 
Klein P, Leitl B, Schatzmann M. 2007. Driving physical mechanisms of flow and dispersion in urban canopies. Int. J. Climatol. 27: 1887-1908

Launiainen S, Vesala T, Molder M, Mammarella I, Smolander S, Rannik Ü, Kolari P, Hari P, Lindroth A, Katul GG. 2007. Vertical variability and effect of stability on turbulence characteristics down to the floor of a pine forest. Tellus 59B: 919-936.

Mahrt L. 1998. Stratified atmospheric boundary layers and breakdown of models. Theoret. Comput. Fluid Dynamics 11: 263-279.

Moran SM, Pardyjak ER, Veranth JM. 2013. Understanding the role of grid turbulence in enhancing pm10 deposition: Scaling the stokes number with $\mathrm{R}_{\lambda}$. Phys. Fluids $\mathbf{2 5}$ : 115103.

Novak MD, Warland JS, Orchansky AL, Ketler R, Green S. 2000. Wind tunnel and field measurements of turbulent flow in forests. Part I: Uniformly thinned stands. Boundary-Layer Meteorol. 95: 457-495.

Okubo A, Levin SA. 1989. A Theoretical Framework for Data Analysis of Wind Dispersal of Seeds and Pollen. Ecology 70: 329-338.

Pardyjak E, Cuerva A. 2007. Sonic anemometry/thermometry. In C Tropea and JF Foss (Eds.), Springer Handbook of Experimental Fluid Mechanics. Springer: New York, 1 edn, pp. 436-446.

Pardyjak ER, Speckart SO, Yin F, Veranth JM. 2008. Near source deposition of vehicle generated fugitive dust on vegetation and buildings: Model development and theory. Atmos. Environ. 42: 6442-6452.

Patton EG, Shaw RH, Judd MJ, Raupach MR. 1998. Large-eddy simulation of windbreak flow. Boundary-Layer Meteorol. 87: 275-306.

Patton EG, Horst TW, Sullivan PP, Lenschow DH, Oncley SP, Brown WOJ, Burns SP, Guenther AB, Held A, Karl T, Mayor SD, Rizzo LV, Spuler SM, Sun J, Turnipseed AA, Allwine EJ, Edburg SL, Lamb BK, Avissar R, Calhoun RJ, Kleissl J, Massman WJ, Paw U KT, Weil JC. 2011. The canopy horizontal array turbulence study. Bull. Amer. Meteor. Soc. 92: 593-611.

Peterson H, Mazzolini D, O’Neill S, Lamb B. 1999. Instantaneous spread of plumes in the surface layer. J. Appl. Meteor. 38: 343-352.

Poggi D, Porporato A, Ridolfi L, Albertson JD, Katul GG. 2004. The effect of vegetation density on canopy sub-layer turbulence. Boundary-Layer Meteorol. 111: 565587.

Prussin AJ, Marr LC, Schmale DG, Stoll R, Ross SD. 2014. Experimental validation of a long-distance transport model for plant pathogens: Application to Fusarium graminearum. Agric. For. Meteorol. 203: 118-130.

Raupach MR, Thom AS, Edwards I. 1980. A wind-tunnel study of turbulent flow close to regularly arrayed rough surfaces. Boundary-Layer Meteorol. 18: 373-397.

Raupach MR, Woods N, Dorr G, Leys JF, Cleugh HA. 2001. The entrapment of particles by windbreaks. Atmos. Environ. 35: 3373-3383. 
Raynor GS, Hayes JV, Ogden EC. 1970. Experimental data on ragweed pollen dispersion and deposition from point and area sources. BNL Rept. 50224 (T-564) Brookhaven National Laboratory, Upton, N.Y. pp. 33.

Raynor GS, Hayes JV, Ogden EC. 1974. Particulate dispersion into and within a forest. Boundary-Layer Meteorol. 7: 429-456.

Skelsey P, Holtslag AAM, van der Werf W. 2008. Development and validation of a quasi-Gaussian plume model for the transport of botanical spores. Agric. For. Meteorol. 148: 1383-1394.

Speckart SO, Pardyjak ER. 2014. A method for rapidly computing windbreak flow field variables. J. Wind Eng. Ind. Aerodyn. 132: 101-108

Stockie JM. 2011. The mathematics of atmospheric dispersion modelling. SIAM Review 53: 349-372.

Su H-B, Schmid HP, Vogel CS, Curtis PS. 2008. Effects of canopy morphology and thermal stability on mean flow and turbulence statistics observed inside a mixed hardwood forest. Agric. For. Meteorol. 148: 862-882.

Su H-B, Shaw RH, Paw U KT, Moeng C-H, Sullivan PP. 1998. Turbulent statistics of neutrally stratified flow within and above a sparse forest from large-eddy simulation and field observations. Boundary-Layer Meteorol. 88: 363-397.

Talaie A, Shojaie-Saadee M, Dadashpour A, Asgari-Sarcheshmeh MA. 2011. Fruit quality in five apple cultivars trees trained to intensive training system: Geneva ytrellis. GENETIKA 43: 153-161.

Tarara JM, Ferguson JC, Hoheisel G-A, Perez Peña JE. 2005. Asymmetrical canopy architecture due to prevailing wind direction and row orientation creates an imbalance in irradiance at the fruiting zone of grapevines. Agric. For. Meteorol. 135: 144-155.

Taylor GI. 1921. Diffusion by continuous movements. Proc. Lond. Math. Soc. 20: 196211.

Thiessen LD, Keune JA, Neill TM, Turechek WW, Grove GG, Mahaffee WF. 2015. Development of a grower performed inoculum detection assay for management of grape powdery mildew. Plant Pathology Accepted.

Thomas C, Foken T. 2007. Flux contribution of coherent structures and its implications for the exchange of energy and matter in a tall spruce canopy. Boundary-Layer Meteorol. 123: 317-337.

Turner DB. 1994. Workbook of atmospheric dispersion estimates: An introduction to dispersion modeling. CRC Press: Boca Raton, 2nd edn. p. 192.

USDA National Agricultural Statistics Service (USDA NASS). 2013. Noncitrus fruits and nuts 2012 preliminary summary. Available at: http://usda.mannlib.cornell.edu/MannUsda/viewDocumentInfo.do?documentID=1113.

Verhoef A, De Bruin HAR, Van Den Hurk BJJM. 1997. Some practical notes on the parameter $\mathrm{kB}^{-1}$ for sparse vegetation. J. Appl. Meteor. 36: 560-572. 
Venkatram A, Snyder MG, Heist DK, Perry SG, Peterson WB, Isakov V. 2013. Reformulation of plume spread for near-surface dispersion. Atmos. Environ. 77: 846855 .

Waterhouse GM. 1973. Peronosporales. In GC Ainsworth, FK Sparrow, and AS Sussman (Eds.), The Fungi: an Advanced Treatise. Vol. 45. Academic Press: New York, pp. 165-183.

Weiss A, Allen Jr LH. 1976. Air-flow patterns in vineyard rows. Agric. For. Meteorol. 16: $329-342$.

Whiteman CD. 2000. Mountain meteorology: Fundamentals and applications. Oxford University Press: New York and Oxford. p. 376.

Yang B, Morse AP, Shaw RH, Paw U KT. 2006. Large-eddy simulation of turbulent flow across a forest edge. Part II: momentum and turbulent kinetic energy budgets. Boundary-Layer Meteorol. 121: 433-457.

Yee E, Biltoft CA. 2004. Concentration fluctuation measurements in a plume dispersing through a regular array of obstacles. Boundary-Layer Meteorol. 111: 363-415.

Yee E, Gailis RM, Hill A, Hilderman T, Kiel D. 2006. Comparison of wind-tunnel and water-channel simulations of plume dispersion through a large array of obstacles with a scaled field experiment. Boundary-Layer Meteorol. 121: 389-432.

Yue W, Parlange MB, Meneveau C, Zhu W, van Hout R, Katz J. 2007. Large-eddy simulation of plant canopy flows using plant-scale representation. Boundary-Layer Meteorol. 124: 183-203.

\section{Appendix A. Supplementary Material: Figures}

\section{Appendix B. Supplementary Material: Data}



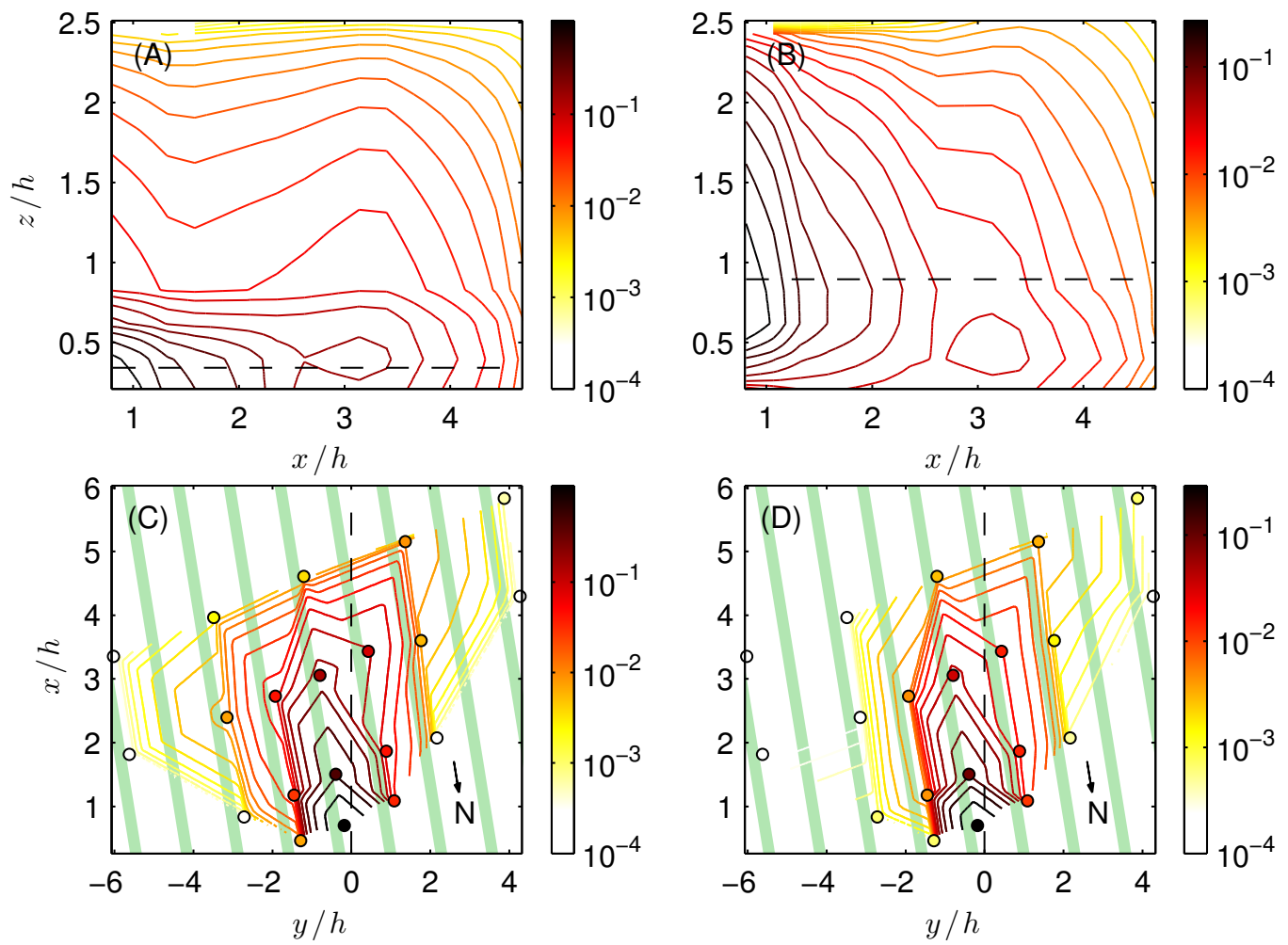

Figure A1: Scaled concentrations (П), on a logarithmic scale, from release event 1. (A) and (B) depict the interpolation onto the $x-z$ plane for the plumes with $H_{r}=0.7 \mathrm{~m}$ and $H_{r}=1.7 \mathrm{~m}$, respectively. The black dashed lines in (A) and (B) represent $H_{r}$ and the wind was from left to right. (C) and (D) depict the $x-y$ planes for the plume with $H_{r}=0.7 \mathrm{~m}$ and $H_{r}=1.7 \mathrm{~m}$, respectively, taken at the impaction trap height just below $H_{r}$. The isolines depict the interpolated data while the $\Pi$ values determined from the impaction traps at their respective locations are shown as the colored circles. The black dashed lines in (C) and (D) represent $\overline{w d}$, the wind is from bottom to top, and the green patches represent the vine rows. 

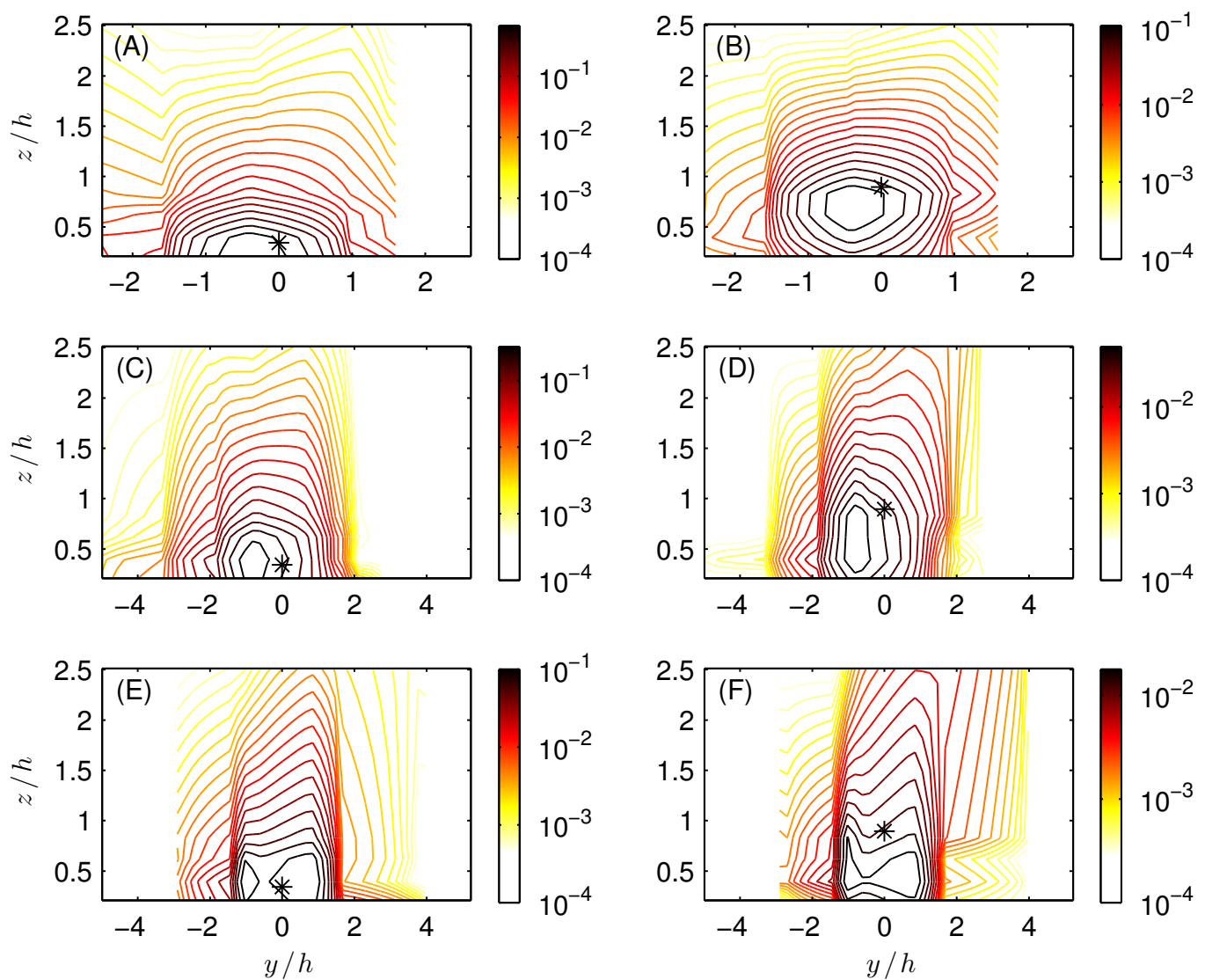

Figure A2: Scaled concentrations $(\Pi)$, on a log-scale, at the three cross-wind interpolation planes as viewed from the source location looking along the $x$ axis for release event 1. (A), (C), and (E) depict the plume with $H_{r}=0.7 \mathrm{~m}$ while (B), (D), and (F) depict the plume with $H_{r}=1.7 \mathrm{~m}$. (A) and (B) are at $x=1.57 h,(\mathrm{C})$ and (D) are at $x=2.89 h$, and (E) and (F) are at $x=4.21 h$. The ' * ' symbols depict the source location on the $x$ axis (i.e. at $H_{r}$ and $y=0$ ). 

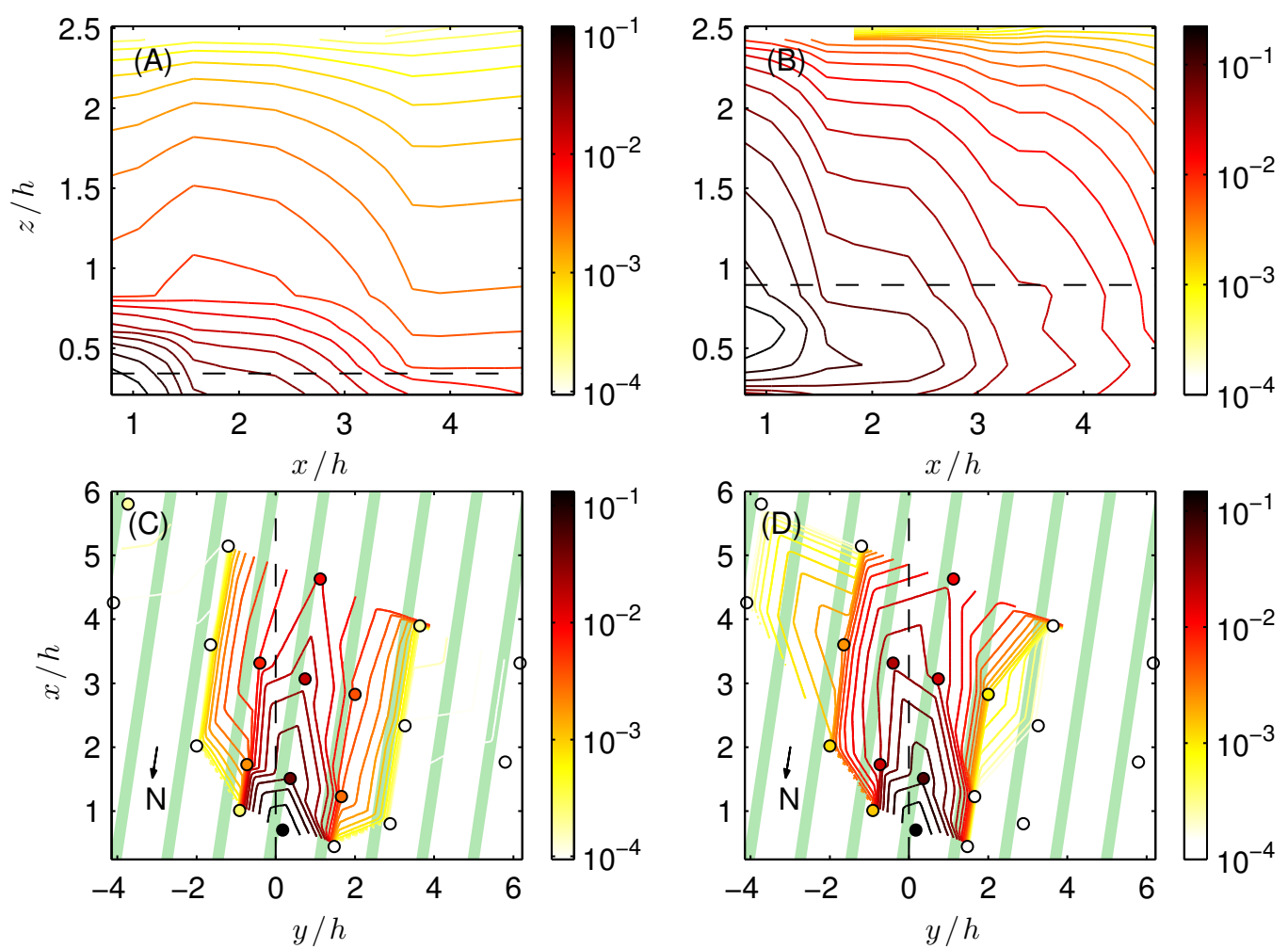

Figure A3: Same as Fig. A1, but for release event 2. 

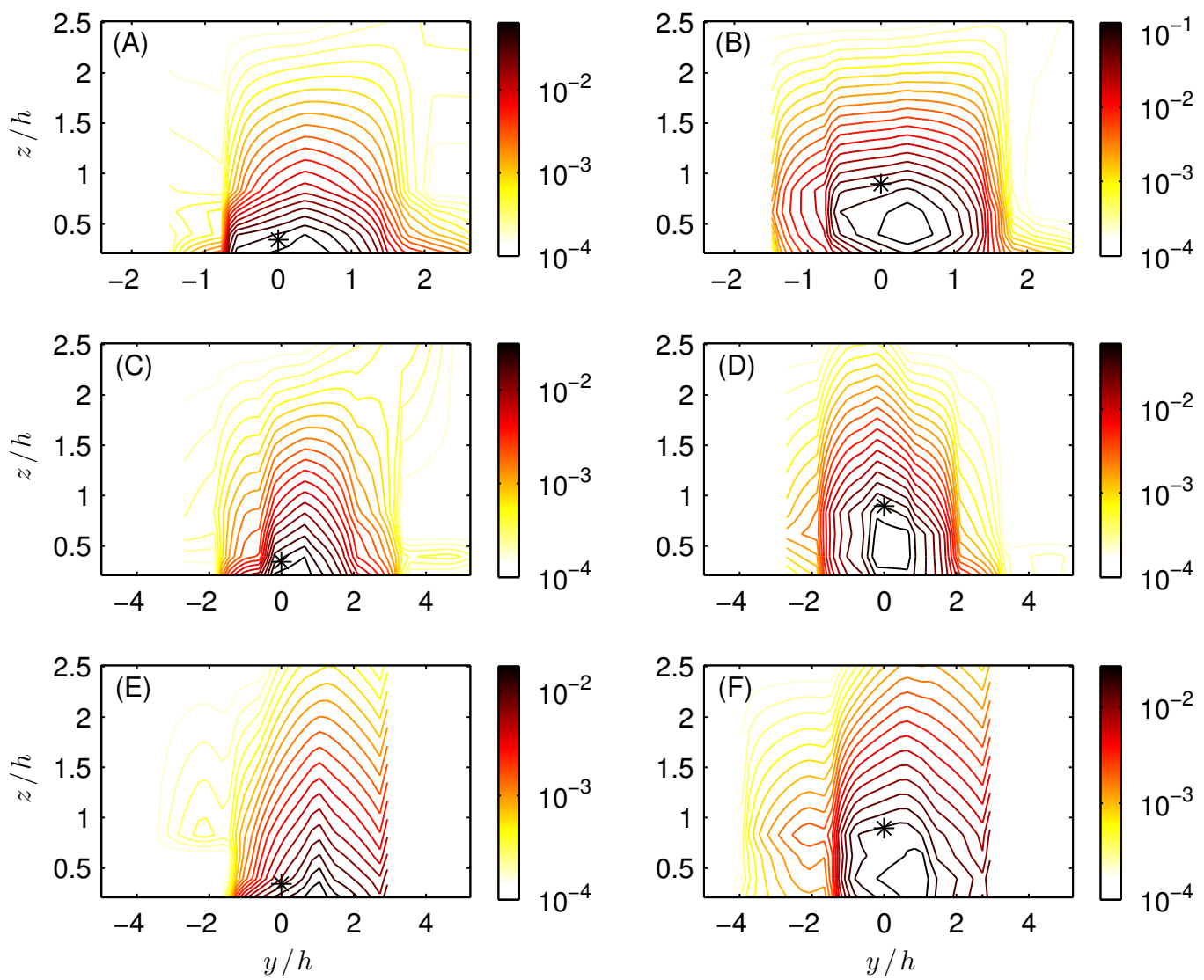

Figure A4: Same as Fig. A2, but for release event 2. 

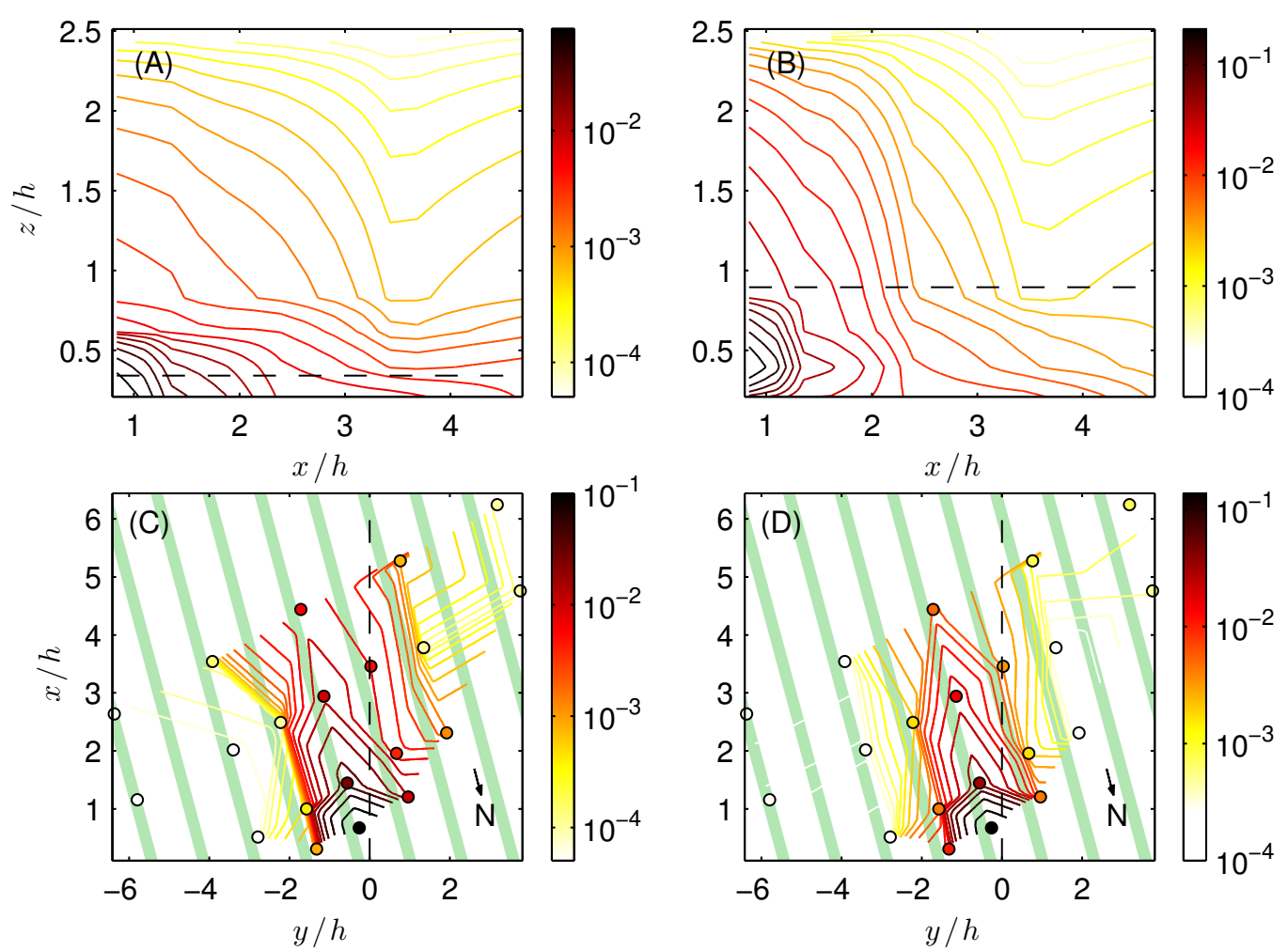

Figure A5: Same as Fig. A1, but for release event 3. 

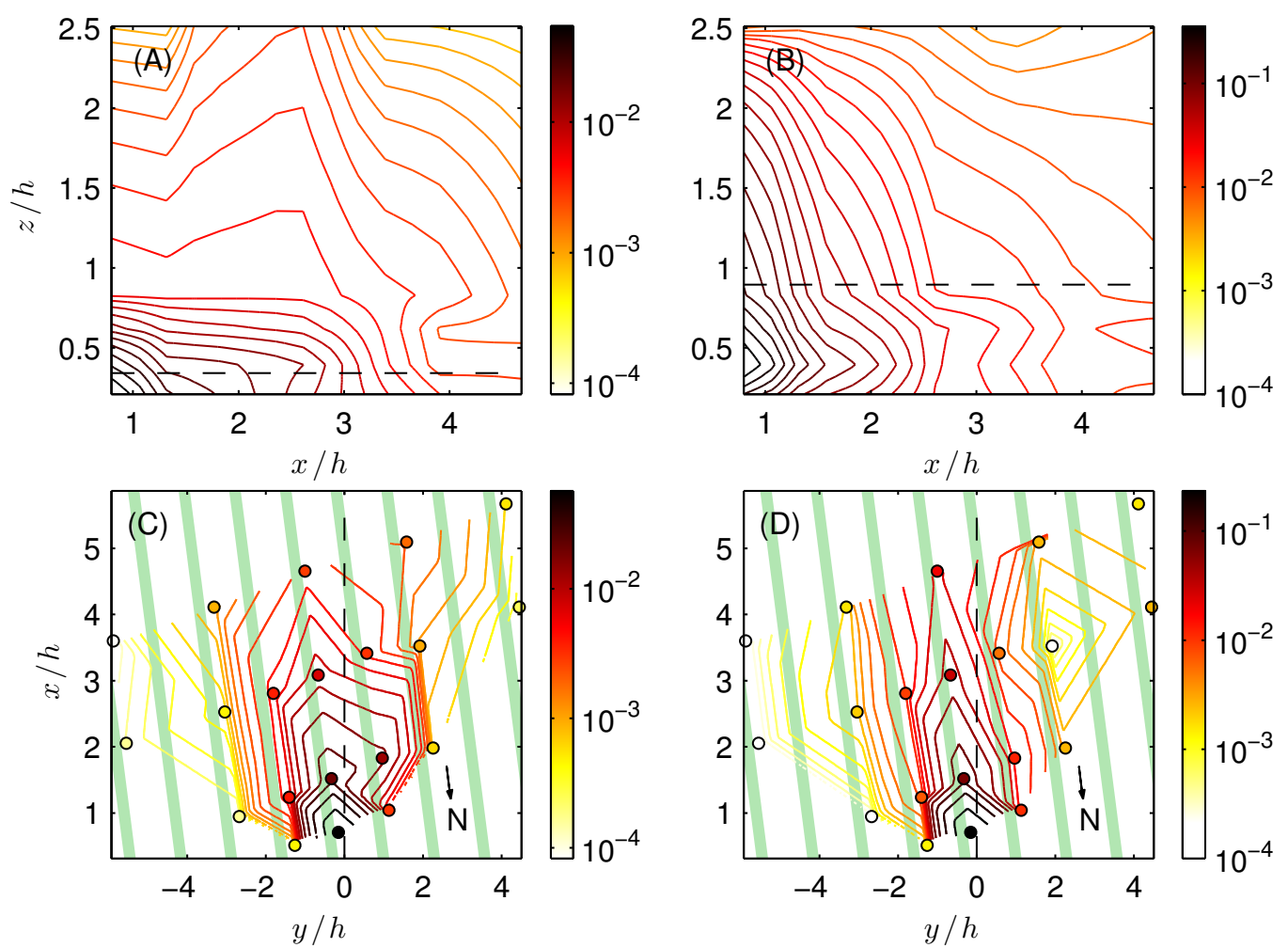

Figure A6: Same as Fig. A1, but for release event 4. 

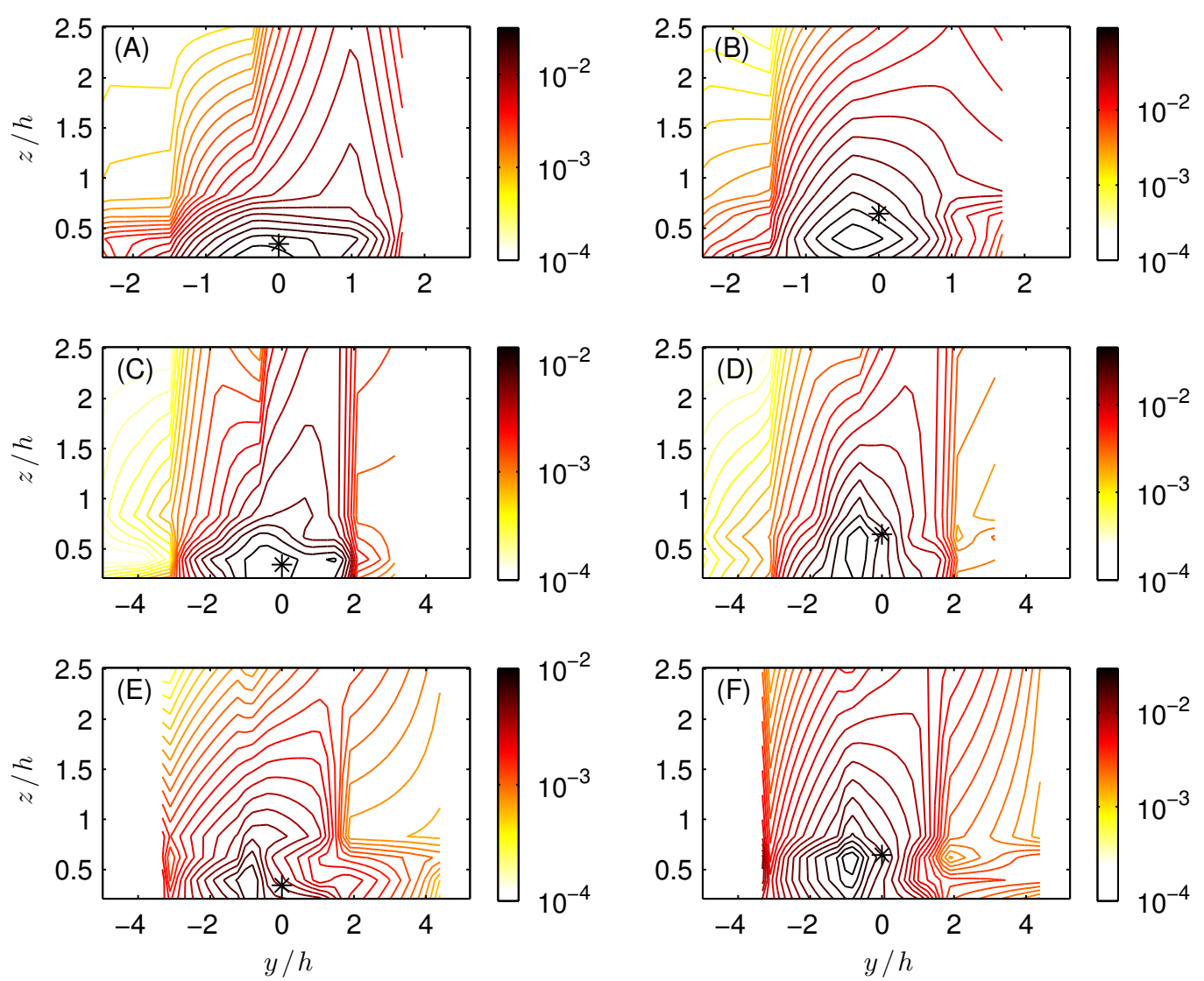

Figure A7: Same as Fig. A2, but for release event 4. 

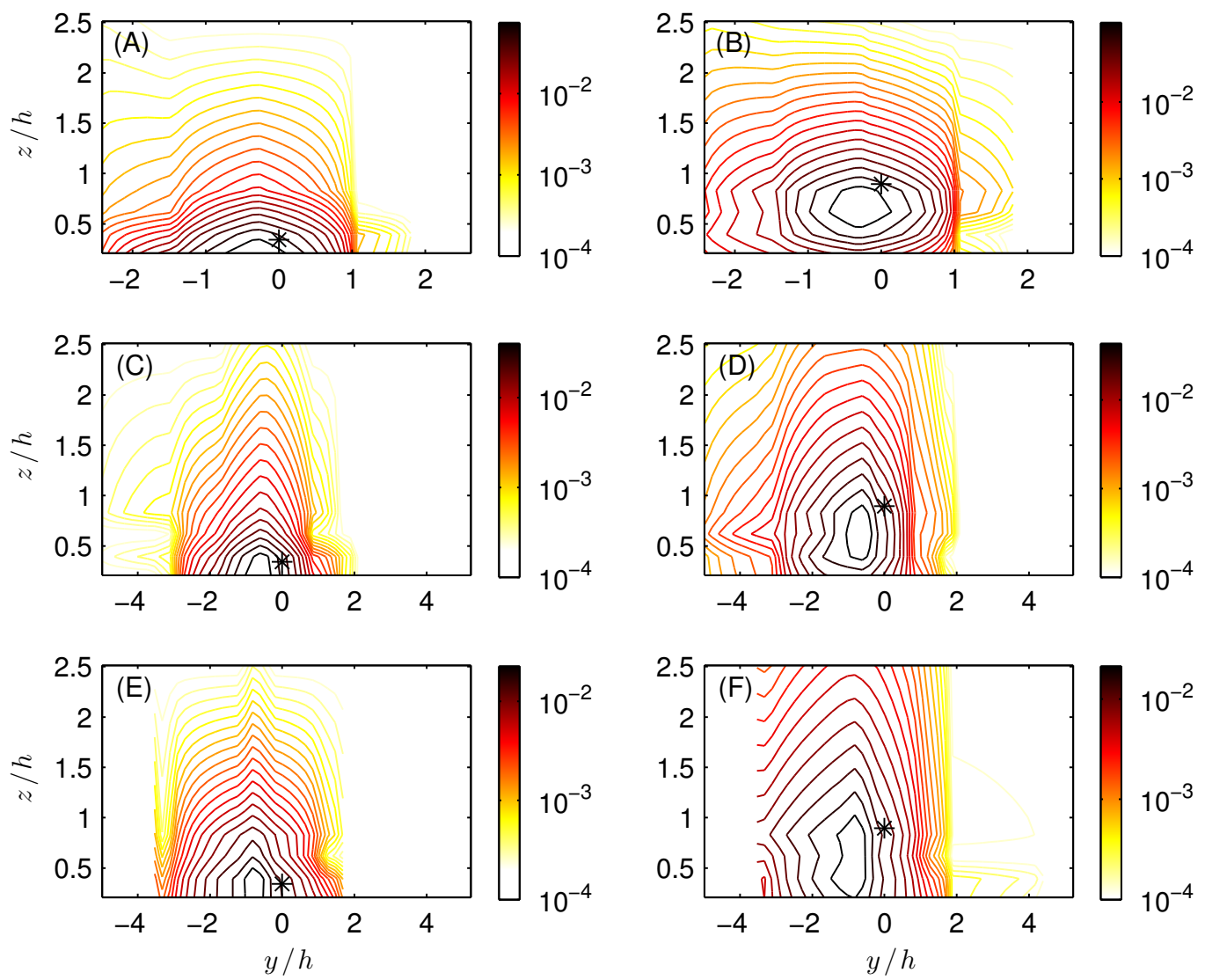

Figure A8: Same as Fig. A2, but for release event 5. 

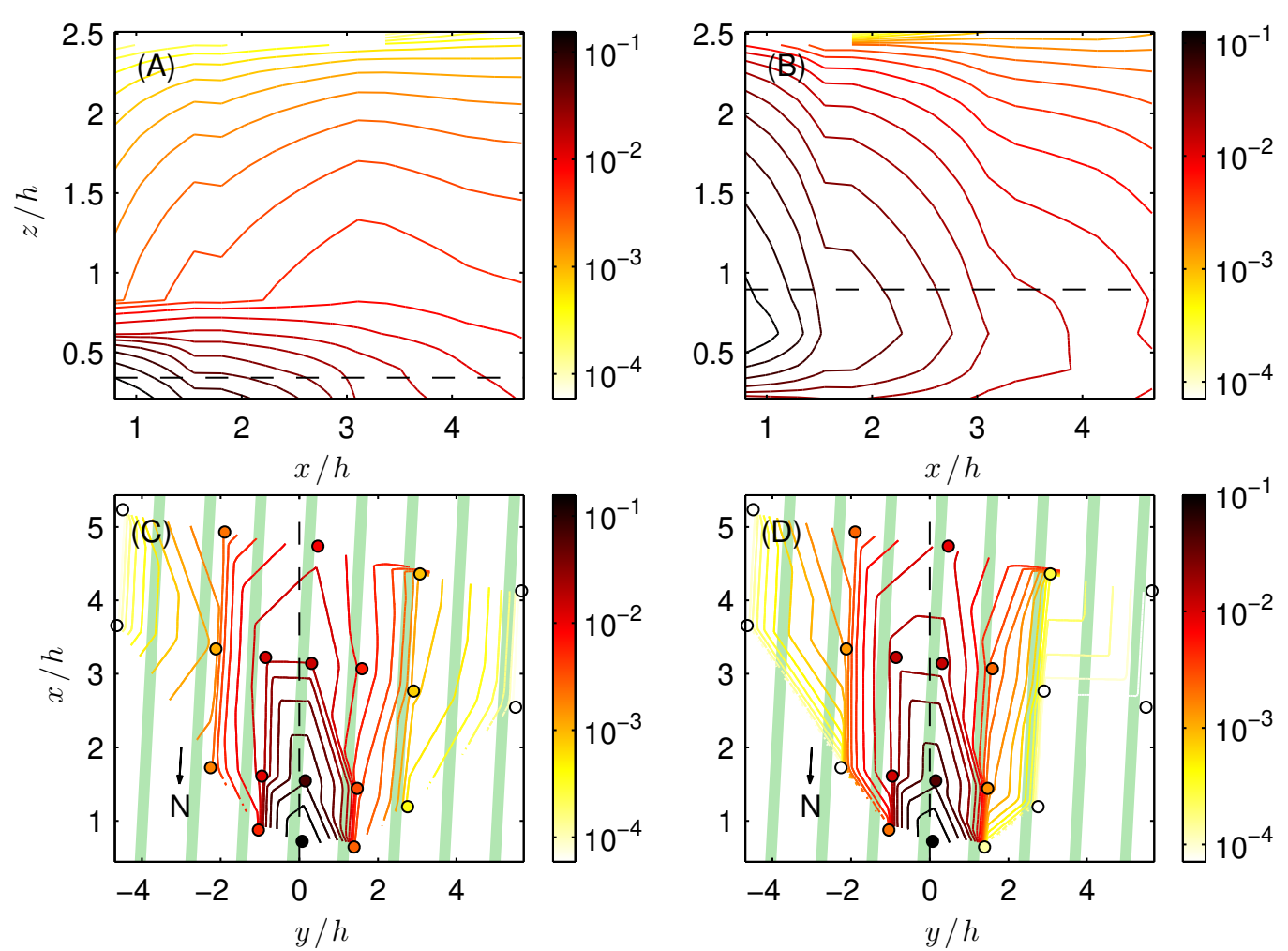

Figure A9: Same as Fig. A1, but for release event 6. 

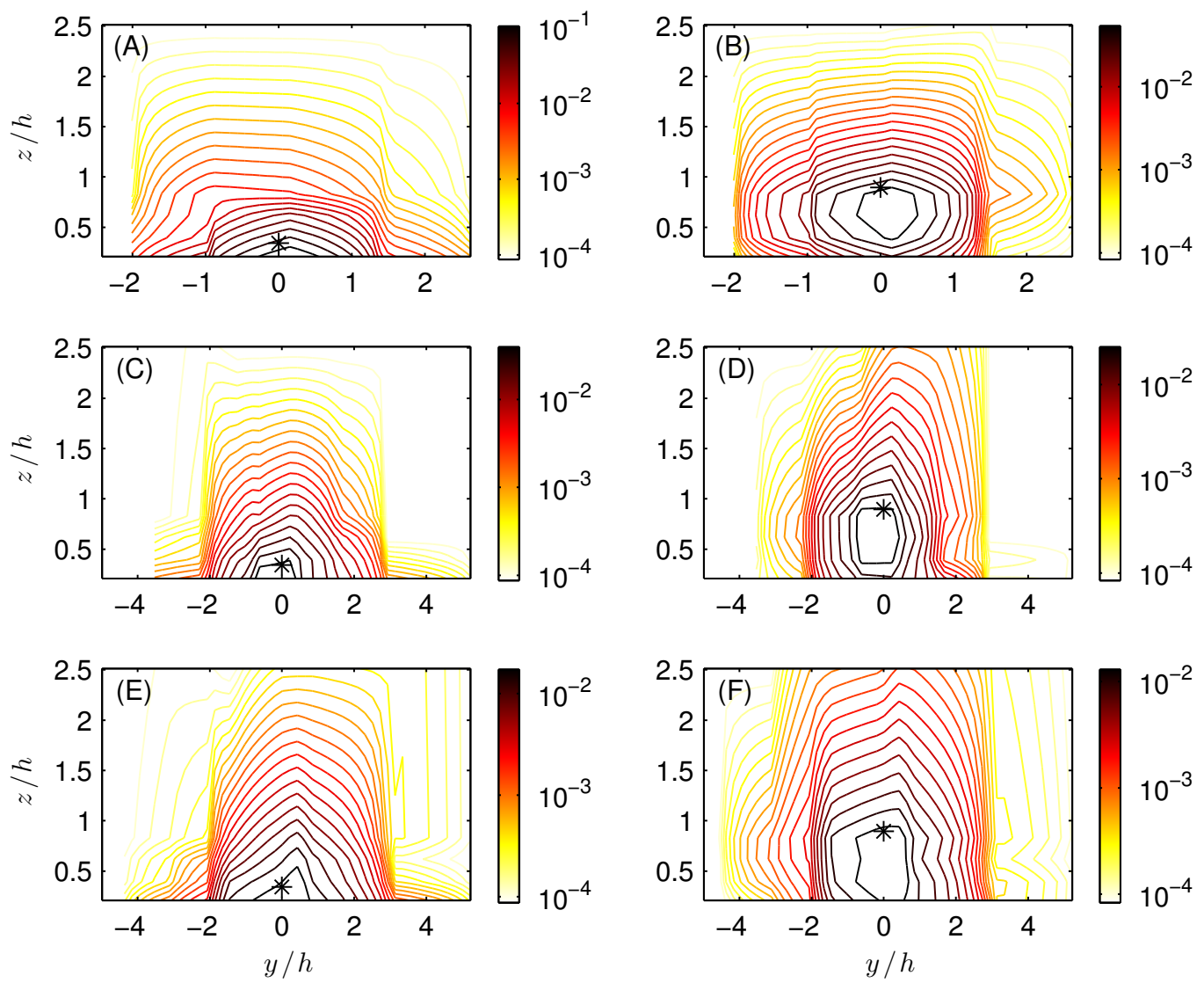

Figure A10: Same as Fig. A2, but for release event 6 . 